NASA Contractor Repoft 4030

\title{
Structural Properties of Bismuth-Bearing Semiconductor Alloys
}

\author{
Martha A. Berding, A. Sher, \\ and A.-B. Chen
}

CONTRACT NAS1-18180

DECEMBER 1986

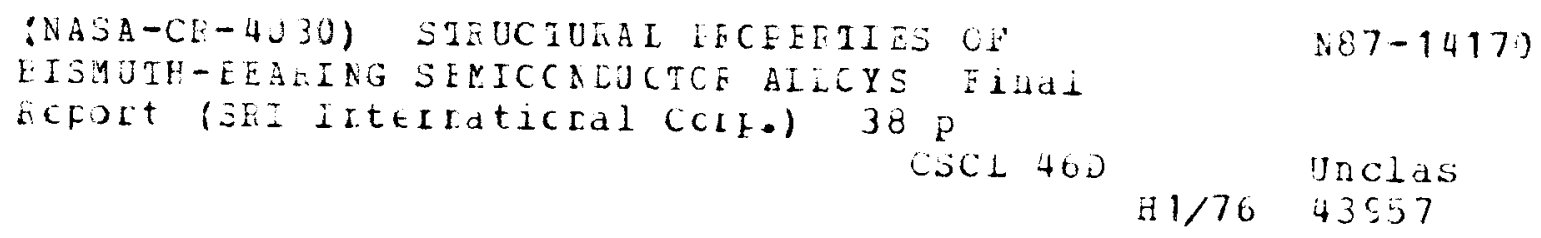


NASA Contractor Report 4030

\section{Structural Properties \\ of Bismuth-Bearing \\ Semiconductor Alloys}

Martha A. Berding and A. Sher

SRI International

Menlo Park, California

A.-B. Chen

Auburn University

Auburn, Alabama

Prepared for

Langley Research Center

under Contract NAS1-18180

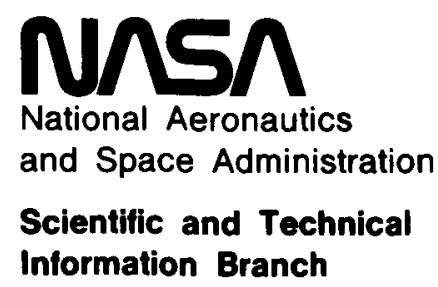

1986 


\section{CONTENTS}

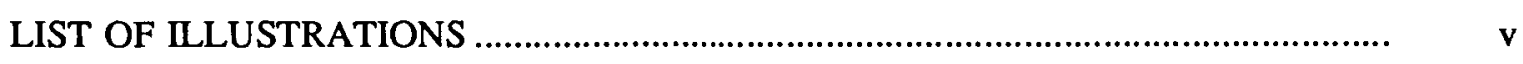

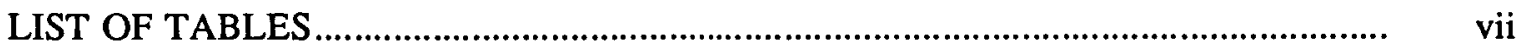

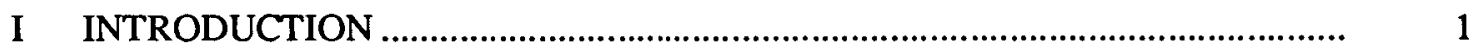

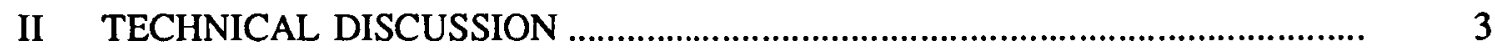

A. Task 1-Literature Search ................................................................... 3

B. Task 2-Bond Energies, Bond Lengths, and Strain Coefficients for Pure Compounds............................................. 3

C. Task 3-Bond Energies, Bond Lengths, and Strain Coefficients for Alloys ....................................................... 6

D. Task 4-Mixing Enthalpy, Miscibility Gaps, and Critical Temperatures ......................................................................... 8

E. Task 5-Cluster Formation..................................................................... 12

F. Task 6-Semiconductor Hardness ..................................................... 15

G. Task 7-Vacancy Formation Energy .................................................. 26

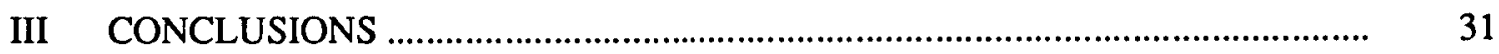

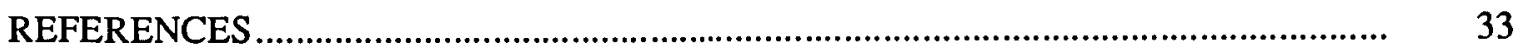




\section{ILLUSTRATIONS}

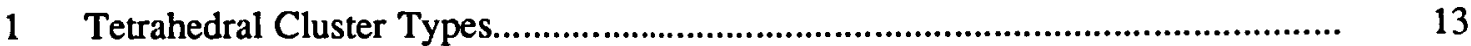

2 Cluster Energies as a Function of Concentration for InSbBi ................................. 14

3 Deviations of Cluster Populations from a Random Distribution as a Function of Concentration for InSbBi ...................................................... 16

4 Alloy Bond Lengths as a Function of Concentration for InSbBi

5 Mixing Free Energies as a Function of Concentration for InSbBi

6 Cluster Energies as a Function of Concentration for InAsBi

7 Deviations of Cluster Populations from Random Distributions as a Function of Concentration for InAsBi

8 Alloy Bond Lengths as a Function of Concentration for InAsBi.

9 Mixing Free Energy as a Function of Concentration for InAsBi 


\section{TABLES}

1 Compound Bond Lengths and Bond Energies ................................................ 4

2 Calculated and Experimental Elastic Constants...................................................... 7

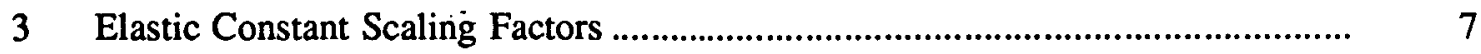

4 Alloy Impurity Bond Lengths...................................................................... 9

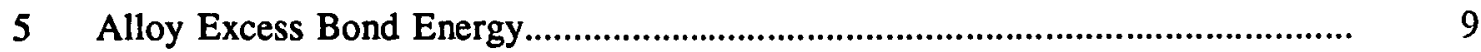

6 Mixing Enthalpy Parameter $\Omega$

for Bismuth Zincblende Alloys .............................................................................. 10

7 Critical Temperature, $T_{\mathrm{C}}$, Melting Temperature,

$\mathrm{T}_{\mathrm{m}}$, Lattice Mismatch Parameter, $\delta_{0}$,

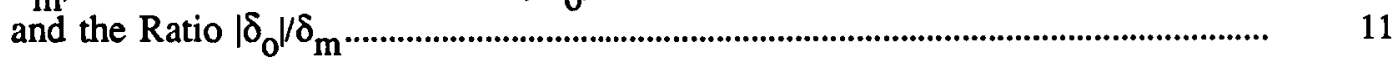

8 Hardness Values of Semiconductors ................................................................... 25

9 Vacancy Formation Energies for Bi Compounds and Other

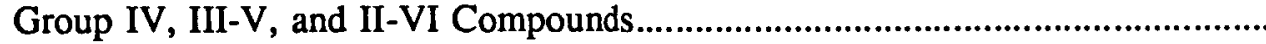




\section{INTRODUCTION}

This is the final report on SRI Project 1452 under NASA contract NAS1-18180 to investigate the structural properties of bismuth-bearing semiconducting alloys.

Although the III-V bismuth compounds do not crystallize in zincblende structures, if such compounds could be grown, they would be expected to have semimetallic properties. When they are alloyed with positive-band-gap III-V compounds, they should produce narrow, positive-gap semiconductors, which would be candidates for use in infrared detection devices. Current materials with such narrow band gaps have notoriously poor structural properties. The purpose of this investigation has been to determine whether the structural properties of the bismuth-bearing alloys appear to justify a major program to grow them. To this end, we have calculated the structural properties expected for the bismuth-bearing alloys; the anionsubstituted alloys $\operatorname{InSb}_{1-x} \mathrm{Bi}_{x}$, InAs ${ }_{1-x} \mathrm{Bi}_{x}$, and $\operatorname{InP}_{1-x} \mathrm{Bi}_{x}$; and the cation-substituted alloys $\mathrm{Ga}_{1-\mathrm{x}} \mathrm{In}_{\mathrm{x}} \mathrm{Bi}, \mathrm{Al}_{1-\mathrm{x}} \mathrm{In}_{\mathrm{x}} \mathrm{Bi}$, and $\mathrm{Al}_{1-\mathrm{x}} \mathrm{Ga}_{\mathrm{x}} \mathrm{Bi}$.

This report is organized according to items on the research task list of the contract:

Task 1:

Conduct a literature search designed to gather the input parameters needed to calculate the structural properties of the Bi-bearing alloys $\operatorname{InSb}_{1-x} B i_{x}, \operatorname{InAs} s_{1-x} B i_{x}, \operatorname{InP}_{1-x} B i_{x}, G a_{1-x} I_{x} B i, A l_{1-x} I_{x} B i, A l_{1-x} G_{x} B i$.

Task 2:

Calculate the bond energies, bond lengths, and strain coefficients for the pure compounds $\mathrm{AlBi}, \mathrm{GaBi}$, and $\mathrm{InBi}$.

Task 3:

Use the results of Task 2 and similar information already at SRI's disposal for other compounds to calculate bond length, bond energy, and strain coefficient modifications occurring in the alloys.

Task 4:

Calculate the mixing enthalpy for the Bi-bearing alloys; then predict miscibility gaps and critical metastable-to-stable material transitemperatures.

Task 5: Calculate tendencies toward micro- and macro-cluster formation.

Task 6: $\quad$ Calculate the hardness of the alloys listed in Task 1.

Task 7: $\quad$ Calculate vacancy formation energies.

Task 8: $\quad$ Prepare and submit reports. 


\section{TECHNICAL DISCUSSION}

\section{A. Task 1-Literature Search}

SRI conducted a literature search to determine the current status of research concerning the growth of bismuth-bearing alloys and to gather the needed input parameters for theoretical calculations.

We found reports of the growth of only one bismuth-bearing zincblende alloy in the literature (Jean-Louis and Hamon, 1969a,b; Joukoff and Jean-Louis, 1972; Oe et al., 1981; Noreika et al., 1982, 1983). Using equilibrium growth methods, $\operatorname{InSb}_{1-\mathrm{x}} \mathrm{Bi}_{\mathrm{x}}$ alloys were grown with up to $\sim 2.6$ mole percent bismuth, the solid-solubility limit of InBi in InSb. Metastable solid solutions of $\mathrm{InSb}_{1-\mathrm{x}} \mathrm{Bi}_{\mathrm{x}}$ were grown by Zilko and Green $(1978 ; 1980)$; up to 12 mole percent InBi was incorporated into InSb, with the semimetal-semiconductor transition occurring at -11 mole percent at $20 \mathrm{~K}$. They found the metastable $\mathrm{InSb}_{1-\mathbf{x}} \mathrm{Bi}_{\mathbf{x}}$ to have good temporal and thermal stability against phase separation.

The primary parameters used in the theoretical calculations of the structural properties of the Bi-bearing alloys are the atomic energy levels of the constituents and the bismuth zincblende-compound bond lengths. None of the bismuth compounds crystalize in a zincblende structure; the only binary compound reported in the literature is $\operatorname{InBi}$, which forms a tetragonal structure similar to $\mathrm{PbO}$ (Wykoff, 1963). Thus, no experimental values were available for the tetrahedral bond lengths for $\mathrm{AlBi}, \mathrm{GaBi}$, and $\mathrm{InBi}$. In addition, no measurements were found reported in the literature of the properties studied theoretically here, e.g. hardness, bond energies, and vacancy formation energies.

\section{B. Task 2-Bond Energies, Bond Lengths, and Strain Coefficients for Pure Compounds}

Although $\mathrm{AlBi}, \mathrm{GaBi}$, and $\mathrm{InBi}$ do not form zincblende structures, the tetrahedral bond lengths for these compounds are a necessary input to the alloy structural calculations. Because no experimental bond lengths are available, SRI determined the zincblende bond lengths theoretically. Throughout this report, we refer to the zincblende bond lengths of InBi, GaBi, and $\mathrm{AlBi}$, although the materials described by these bond lengths have never been grown. For the anion-substituted alloys, $\operatorname{InA}_{1-\mathrm{x}} \mathrm{Bi}_{\mathrm{x}}$ where $\mathrm{A}=\mathrm{P}, \mathrm{As}$, or $\mathrm{Sb}$, the bond lengths are perhaps most accurately interpreted as the limit of the zincblende alloy bond length as the concentration, $\mathrm{x}$, approaches 1 .

The experimental data for $\operatorname{InSb}_{1-\mathrm{x}} \mathrm{Bi}_{\mathrm{x}}$ with $\mathrm{x}<0.03$ (Joukoff and Jean-Louis, 1972) were used to extrapolate the bond length of zincblende InBi, assuming Vegard's law holds; that is, that the alloy bond length varies linearly with concentration. The bond lengths of InP, InAs, InSb, InBi, GaBi, and AlBi were computed by two methods. First, SRI used Pauling covalent 
radii $(\mathrm{R})$ and known III-V compound bond lengths (including the InBi bond length extrapolated from the alloy data) to deduce $\mathrm{Bi}$ and cation covalent radii. From these radii, the compound bond lengths, $d$, were computed from

$$
\mathrm{d}=\mathrm{R} \text { (cation) }+\mathrm{R} \text { (anion) }
$$

Second, SRI used Harrison's theory (Harrison, 1980; 1983) to predict zincblende bond lengths. For compounds of known bond lengths, this theory yields exact agreement with experiment, because the model incorporates the experimental bond lengths into the determination of the repulsive overlap energy, $\mathrm{V}_{0}$. For $\mathrm{GaBi}$ and $\mathrm{AlBi}$ compounds with unknown bond lengths, appropriately averaged coefficients were used in the calculation of $V_{0}$. Calculated bond lengths are summarized in Table 1 . Note that the bond lengths calculated from covalent radii and Harrison's model give agreement within 2 percent.

Table 1

\section{COMPOUND BOND LENGTHS AND BOND ENERGIES}

\begin{tabular}{|l|c|c|c|c|c|c|}
\hline & \multicolumn{3}{|c|}{ Bond Length $(\AA)$} & \multicolumn{3}{c|}{ Bond Energy (eV) } \\
\cline { 2 - 7 } Compound & Experiment & $\begin{array}{c}\text { Covalent } \\
\text { Radii }\end{array}$ & $\begin{array}{c}\text { Harrison's } \\
\text { Theory }\end{array}$ & Experiment & $\begin{array}{c}\text { Harrison's } \\
\text { Theory }\end{array}$ & $\begin{array}{c}\text { Current } \\
\text { Work }\end{array}$ \\
\hline InP & 2.54 & 2.51 & 2.54 & -1.74 & -2.05 & -1.98 \\
InAs & 2.62 & 2.62 & 2.61 & -1.55 & -1.72 & -1.58 \\
InSb & 2.81 & 2.82 & 2.81 & -1.40 & -1.24 & -1.00 \\
InBi & $2.88^{*}$ & 2.88 & 2.88 & + & -1.16 & -0.53 \\
GaBi & + & 2.72 & 2.68 & + & -1.47 & -0.87 \\
$\mathrm{AlBi}$ & + & 2.71 & 2.72 & + & -1.60 & -1.02 \\
$\mathrm{ZnTe}$ & & & & -1.20 & -1.03 & -0.87 \\
$\mathrm{CdTe}$ & & & & -1.10 & -0.96 & -0.81 \\
$\mathrm{HgTe}$ & & & & -0.82 & -0.48 & -0.32 \\
\hline
\end{tabular}

${ }^{*}$ Extrapolated from the $\mathrm{InSb}_{1-\mathrm{x}} \mathrm{Bi}_{\mathrm{x}}$ alloy bond lengths.

${ }^{+}$No experimental values available.

Bond energies were computed from Harrison's model, using the zincblende bond lengths calculated above. The bond energy is given by (Sher et al., 1985a)

$$
\mathrm{E}_{\mathrm{b}}=2 \varepsilon_{\mathrm{b}}+2\left(\varepsilon_{\mathrm{met}}^{\mathrm{a}}+\varepsilon_{\mathrm{met}}^{\mathrm{b}}\right)+\mathrm{V}_{0}+\mathrm{E}_{\mathrm{tr}}+\mathrm{E}_{\mathrm{pro}}{ }^{\mathrm{a}}+\mathrm{E}_{\mathrm{pro}}{ }^{\mathrm{c}}
$$


where $\varepsilon_{\mathrm{b}}$ is the bond formation energy; $\varepsilon_{\text {met }}{ }^{\mathrm{a}}$ and $\varepsilon_{\text {met }}{ }^{\mathrm{c}}$ are the metallization energies from coupling through the anion and cation sites, respectively; $V_{0}$ is the repulsive overlap energy;

$$
\begin{aligned}
& \mathrm{E}_{\mathrm{tr}}=\mathrm{n}\left(\varepsilon_{\mathrm{p}}{ }^{\mathrm{c}}-\varepsilon_{\mathrm{p}}{ }^{\mathrm{a}}\right) / 4 \\
\mathrm{n}= & 1 \text { for group IV compounds } \\
& 2 \text { for II-VI compounds } \\
&
\end{aligned}
$$

is the energy per bond necessary to transfer $\mathrm{n}$ electrons from an anion to a cation site, where $\varepsilon_{\mathrm{s}}^{\mathrm{a}}, \varepsilon_{\mathrm{p}}^{\mathrm{a}}, \varepsilon_{\mathrm{s}}^{\mathrm{c}}$, and $\varepsilon_{\mathrm{p}}^{\mathrm{c}}$ are atomic term values; and

$$
E_{p r o}{ }^{a(c)}=\left[\varepsilon_{p}^{a(c)}-\varepsilon_{p}^{a(c)}\right] / 4
$$

is the promotion energy per bond to form $\mathrm{sp}^{3}$ hybrids on the anion (cation) site.

SRI computed atomic term values from an ab-initio total energy calculation based on pseudo-potentials (Bachelet et al., 1982). These calculations include the spin-orbit (SO) interaction, so that the degeneracy of the p-levels is partially removed. The p-levels are split into a deeper singly degenerate state with total angular momentum $J=1 / 2$ and with atomic term value $\varepsilon_{\mathrm{p} 1 / 2}$, and a shallower two-fold degenerate $J=3 / 2$ state, with $\varepsilon_{\mathrm{p} 3 / 2}$. This p-level splitting will have an important effect on the properties considered below and is especially important for the heavier atoms such as bismuth, where this relativistic correction is significant. Harrison's model discussed above does not include this SO splitting into the calculation of the bond energy. It is the last three terms in Eq. (1) which are modified by the inclusion of the SO splitting in the calculation. With SO splitting included, the transfer energy becomes

$$
\mathrm{E}_{\mathrm{tr}}=\mathrm{n}\left(\varepsilon_{\mathrm{p} 1 / 2}^{\mathrm{c}}-\varepsilon_{\mathrm{p} 3 / 2}{ }^{\mathrm{a}}\right)
$$

with $\mathrm{n}$ as given in Eq. (2), and the promotion energy is given by

$$
\mathrm{E}_{\mathrm{pro}}{ }^{\mathrm{a}(\mathrm{c})}=\left[2 \varepsilon_{\mathrm{p} 3 / 2^{\mathrm{a}}}{ }^{(\mathrm{c})}-\varepsilon_{\mathrm{s}}{ }^{\mathrm{a}(\mathrm{c})}-\varepsilon_{\mathrm{p} 1 / 2}{ }^{\mathrm{a}(\mathrm{c})}\right]
$$

In Table 1, we see that the effect of including the SO splitting in the calculations is significant, especially for the compounds containing heavier atoms and results in as much as a 54 percent reduction in the magnitude of the bond energy for the $\mathrm{Bi}$ compounds. The large $\mathrm{SO}$ splitting in $\mathrm{Bi}$, along with the other effects of the relativistic terms which cause a reduction of the s-state energies, is likely to explain why bismuth compounds do not tend to form in tetrahedrally coordinated structures, since it is so costly to promote electrons to form $\mathrm{sp}^{3}$ hybrids. 
Shown for comparison in Table 1 are the bond energies of three II-VI compounds: $\mathrm{ZnTe}, \mathrm{CdTe}$, and HgTe. Compared to these compounds, which form narrow-gap II-VI alloys, the bismuth compounds and their alloys are expected to be more strongly bonded.

SRI computed the elastic constants using Harrison's model for bonding in cubic semiconductors. The bulk modulus, $\mathrm{B}, \mathrm{C}_{11}-\mathrm{C}_{12}$, and $\mathrm{C}_{44}$ can be determined by application of a uniform volume expansion, a shear deformation and a graphite distortion, respectively, to the zincblende structure (Harrison, 1980; 1983; Chen and Sher, 1983). The calculated elastic constants for the six compounds of interest here are given in Table 2. Although the quantitative agreement with the experimental values is poor, in particular for the bulk modulus, which indicates a need for improvement in the theoretical model used, the trends among compounds is properly predicted.

One way in which to improve the quantitative agreement with the experimental elastic constants is through a uniform scaling of the theoretical values. SRI determined scaling factors for $\mathrm{B}, \mathrm{C}_{11}-\mathrm{C}_{12}$, and $\mathrm{C}_{44}$ by a least squares fit to all of the III-V compounds with experimentally known elastic constants. The three scaling constants obtained and the maximum resulting error for any one compound (compared with experiment) are summarized in Table 3.

SRI also calculated the bond-stretching and bond-bending force constants $\alpha$ and $\beta$ for the zincblende structures using the Valence Force Field (VFF) model, discussed by Keating (1966) and Martin (1970). Scaled elastic constants were used; the results are summarized in Table 2.

The elastic constants calculated for the hypothetical zincblende $\mathrm{Bi}$ compounds are larger than the corresponding experimental values for the Te compounds currently used in infrared detectors. Alloying these Bi compounds with some of the others listed in Table 1 could produce a fairly strong and resilient material.

\section{Task 3-Bond Energies, Bond Lengths, and Strain Coefficients for Alloys}

SRI calculated local bond length and bond energy modifications expected in the dilute alloys using a perturbation-expansion form of Harrison's theory as discussed by Chen and Sher (1985a). This formalism permits the inclusion of chemical effects on the bond length shifts as well as the bond strain terms of the Valence Force Field (VFF) model (Keating, 1966). In addition, the perturbation expansion formalism permits the use of measured or theoretical strain coefficients in the VFF, thus avoiding the inadequacy of Harrison's theory in predicting the elastic constants accurately.

By treating the dilute species as an impurity in the host lattice, SRI calculated impurity bond lengths and excess bond energies using the scaled theoretical force constants and strain coefficients. For an alloy $A_{x} B_{1-x} C$ with $x \ll 1$, the excess bond energy, $\Delta E$, is defined as the extra energy per bond required for the impurity substitution over and above the binding-energy difference between the $B C$ and $A C$ crystals. The binding-energy difference accounts for much of the substitution energy; however, the correction measured by the excess energy can be significant. This excess energy results from strain energies and chemically driven charge redistributions around the defect. Several valence force field models were used to calculate the 
Table 2

CALCULATED AND EXPERIMENTAL ELASTIC CONSTANTS

(All values $10^{11}$ dynes $/ \mathrm{cm}^{2}$ unless otherwise noted)

\begin{tabular}{|c|c|c|c|c|c|c|c|c|c|c|c|}
\hline \multirow[b]{2}{*}{ Compound } & \multicolumn{3}{|c|}{ B } & \multicolumn{3}{|c|}{$c_{11} \cdot c_{12}$} & \multicolumn{3}{|c|}{$c_{44}$} & \multirow[b]{2}{*}{$\begin{array}{c}\alpha^{*} \\
(\mathrm{~N} / \mathrm{m})\end{array}$} & \multirow[b]{2}{*}{$\begin{array}{c}\beta^{*} \\
(\mathrm{~N} / \mathrm{m})\end{array}$} \\
\hline & Experimental & Theory & $\begin{array}{l}\text { Scaled } \\
\text { Theory }\end{array}$ & Experimental & Theory & $\begin{array}{l}\text { Scaled } \\
\text { Theory }\end{array}$ & Experimental & Theory & $\begin{array}{l}\text { Scaled } \\
\text { Theory }\end{array}$ & & \\
\hline InP & 7.25 & 2.84 & 6.24 & 4.46 & 4.41 & 5.10 & 4.60 & 3.41 & 4.88 & 34.1 & 7.49 \\
\hline InAs & 5.80 & 2.62 & 5.77 & 3.80 & 3.79 & 4.38 & 3.96 & 2.91 & 4.18 & 32.7 & 6.63 \\
\hline InSb & 4.66 & 1.96 & 4.30 & 3.02 & 2.73 & 3.16 & 3.02 & 2.08 & 2.98 & 26.2 & 5.12 \\
\hline $\operatorname{InBi}$ & - & 1.81 & 3.99 & - & 2.34 & 2.71 & - & 1.82 & 2.61 & 25.0 & 4.51 \\
\hline $\mathrm{GaBi}$ & - & 2.01 & 4.42 & - & 3.15 & 3.64 & - & 2.51 & 3.60 & 25.7 & 5.67 \\
\hline$A \mid B i$ & - & 2.14 & 4.71 & - & 3.16 & 3.65 & - & 2.45 & 3.51 & 27.7 & 5.72 \\
\hline $\mathrm{ZnTe}$ & 5.09 & 2.10 & - & 3.06 & 3.47 & - & 3.12 & 2.80 & - & 29.4 & 4.66 \\
\hline CdTe & 4.24 & 1.41 & - & 1.68 & 2.47 & - & 1.99 & 2.10 & - & 26.6 & 2.72 \\
\hline $\mathrm{HgTe}$ & 4.22 & 1.69 & - & 1.70 & 2.61 & - & 2.11 & 2.10 & - & 26.4 & 2.75 \\
\hline
\end{tabular}

*Calculated using the scaled theory elastic constants for the III-V compounds and the experimental elastic constants for the II-VI compounds.

Table 3

ELASTIC CONSTANT SCALING FACTORS

\begin{tabular}{|c|c|c|}
\hline Constant & Scaling Constant & $\begin{array}{c}\text { Maximum } \\
\text { Error (percent) }\end{array}$ \\
\hline $\mathrm{B}$ & 2.20 & 14 \\
$\mathrm{C}_{11}-\mathrm{C}_{12}$ & 1.16 & 15 \\
$\mathrm{C}_{44}$ & 1.43 & 7 \\
\hline
\end{tabular}


bond length and bond energy modifications occurring in dilute alloys, as discussed in Sher et al. (1985a): model $C$ is a simple spring model where the bond bending force constants, $\beta$, are set to zero and the second-shell atoms are connected to a fixed boundary; model FPT is the full perturbation theory of Chen and Sher (1985a) with a continuum connected to the second-shell atoms; and model D2 is the FPT with all of the chemical terms neglected. Resulting bond lengths and energy modifications using these three models are summarized in Tables 4 and 5 .

The bond length changes for the impurity species is from 20 to 35 percent of the bond length differences between the impurity and host bond lengths, with all impurity bond lengths shifting toward the host bond length. Thus, the impurity bond lengths are nearer the bond lengths of the impurity compound than those of the host compound. The full perturbation theory (FPT) results differ from model D2, which is the full perturbation theory without the chemical terms, by no more than $0.003 \AA$ for all the alloys studied, far less than the experimental accuracy of the extended X-ray absorption fine structure (EXAFS) measurements used to determine alloy bond length shifts.

The excess bond energy is greatest in the ( $\mathrm{P}, \mathrm{Bi})$ In alloy, primarily because of the large strains resulting from the large bond lengths difference between InP and InB (approximately 13 percent). The bond energy shifts due to the chemical terms in the FPT are also most significant for this system. For the nearly lattice matched system $(\mathrm{Ga}, \mathrm{Al}) \mathrm{Bi}$, the bond excess energies are negligible.

SRI began work on the alloy variations of the strain coefficients, although we have not yet made final predictions for the bismuth-bearing alloys. We expect that the dependence on the concentration is not a simple VCA dependence, but rather will exhibit an upward bowing, as does the hardness. The idea proposed previously of modifying Harrison's theory by introducing a new scaling law for the bonding energy and the repulsive energies, and thereby obtaining the correct strain coefficients from the theory directly, lends itself to the prediction of the alloy strain coefficients. But such a calculation depends on knowing the elastic constants $a$ priori, because it is from these that the scaling laws are determined for a given compound. Thus, we cannot determine the dependence of the strain coefficients on the concentration, $x$, in this manner for the bismuth compounds because the elastic constants of these compounds have not been experimentally determined.

\section{Task 4-Mixing Enthalpy, Miscibility Gaps, and Critical Temperatures}

SRI computed the dilute alloy mixing enthalpy as discussed by Chen and Sher (1985a). For modest pressures, the entropy term in the Helmholtz free energy can be neglected, giving, for an alloy $A_{x} B_{1-x} C$,

$$
\Delta H_{m}=\Delta E_{m}=E_{\text {alloy }}-\left[\mathrm{xE}_{\mathrm{AC}}+(1-\mathrm{x}) \mathrm{E}_{\mathrm{BC}}\right],
$$


Table 4

ALLOY IMPURITY BOND LENGTHS (

\begin{tabular}{|l|c|c|c|c|c|c|}
\hline \multicolumn{2}{|c|}{ Compound } & \multicolumn{5}{c|}{ Bond Lengths } \\
\hline Impurity & Host & Impurity & Host & C & D2 & FPT \\
\hline InBi & InP & 2.880 & 2.541 & 2.774 & 2.762 & 2.761 \\
InP & InBi & 2.541 & 2.880 & 2.608 & 2.607 & 2.607 \\
InBi & InAs & 2.880 & 2.622 & 2.802 & 2.796 & 2.796 \\
InAs & InBi & 2.622 & 2.880 & 2.674 & 2.674 & 2.675 \\
InBi & InSb & 2.880 & 2.805 & 2.861 & 2.860 & 2.859 \\
InSb & InBi & 2.805 & 2.880 & 2.823 & 2.823 & 2.823 \\
InBi & $\mathrm{GaBi}$ & 2.880 & 2.700 & 2.834 & 2.828 & 2.825 \\
$\mathrm{GaBi}$ & $\mathrm{InBi}$ & 2.700 & 2.880 & 2.744 & 2.744 & 2.746 \\
InBi & $\mathrm{AlBi}$ & 2.880 & 2.715 & 2.836 & 2.832 & 2.830 \\
$\mathrm{AlBi}$ & $\mathrm{InBi}$ & 2.715 & 2.880 & 2.753 & 2.753 & 2.755 \\
$\mathrm{GaBi}$ & $\mathrm{AlBi}$ & 2.700 & 2.715 & 2.704 & 2.704 & 2.705 \\
$\mathrm{AlBi}$ & $\mathrm{GaBi}$ & 2.715 & 2.700 & 2.711 & 2.711 & 2.710 \\
\hline
\end{tabular}

Table 5

ALLOY EXCESS BOND ENERGY

(kcal/mole-band)

\begin{tabular}{|l|l|c|c|c|}
\hline \multirow{2}{*}{ Impurity } & \multirow{2}{*}{ Host } & \multicolumn{3}{|c|}{ Model } \\
\cline { 3 - 5 } & & D2 & FPT \\
\hline InBi & InP & 1.939 & 2.294 & 2.326 \\
InP & InBi & 1.663 & 1.760 & 1.800 \\
InBi & InAs & 1.091 & 1.235 & 1.254 \\
InAs & InBi & 0.955 & 1.010 & 1.035 \\
InBi & InSb & 0.079 & 0.087 & 0.089 \\
InSb & InBi & 0.077 & 0.081 & 0.083 \\
InBi & GaBi & 0.446 & 0.538 & 0.543 \\
$\mathrm{GaBi}$ & InBi & 0.440 & 0.467 & 0.462 \\
InBi & $\mathrm{AlBi}$ & 0.396 & 0.456 & 0.463 \\
$\mathrm{AlBi}$ & InBi & 0.377 & 0.399 & 0.405 \\
$\mathrm{GaBi}$ & $\mathrm{AlBi}$ & 0.003 & 0.004 & 0.002 \\
$\mathrm{AlBi}$ & $\mathrm{GaBi}$ & 0.003 & 0.004 & 0.002 \\
\hline
\end{tabular}


where $\Delta \mathrm{H}_{\mathrm{m}}$ is the mixing enthalpy and $\Delta \mathrm{E}_{\mathrm{m}}$ is the mixing energy. Equation (6) can be rewritten in terms of the excess free energy per bond, $\Delta \mathrm{E}$, computed above and summarized in Table 5:

$$
\begin{gathered}
\Delta \mathrm{H}_{\mathrm{m}}=\mathrm{x}(1-\mathrm{x}) \Omega, \\
\Omega=2[\Delta \mathrm{E}(\mathrm{A} \text { in } \mathrm{BC})+\Delta \mathrm{E}(\mathrm{B} \text { in } \mathrm{AC})],
\end{gathered}
$$

where $\Omega$ is the mixing enthalpy parameter. From Eq. (7) $\Delta \mathrm{H}_{\mathrm{m}}$ should be viewed as a lower bound on the mixing enthalpy, because measured mixing enthalpies will, in general, be affected by contributions from nonideal structures such as vacancies, impurities, dislocations, grain boundaries, and surface conditions.

Calculated $\Omega$ for the various bismuth zincblende compounds are summarized in Table 6 . We see that the mixing enthalpy parameter is positive for all of the bismuth-bearing alloys, indicating possible miscibility gaps for all alloys. The mixing enthalpy is lowest for $\mathrm{InBi}_{\mathbf{x}} \mathrm{Sb}_{1-\mathrm{x}}$ and $\mathrm{Ga}_{\mathbf{x}} \mathrm{Al}_{1-\mathrm{x}} \mathrm{Bi}$ alloys, which have the smallest lattice mismatch of the constituent compounds, while the mixing enthalpy is largest for $\operatorname{InBi}_{x} \mathrm{P}_{1-x}$, which has the largest compound bond length mismatch of the alloys considered.

Table 6

MIXING ENTHALPY PARAMETER $\Omega$ FOR BISMUTH ZINCBLENDE ALLOYS

$(\mathrm{kcal} / \mathrm{mole})$

\begin{tabular}{|l|c|c|c|}
\hline \multirow{2}{*}{ Compound } & \multicolumn{3}{|c|}{ Model } \\
\cline { 2 - 4 } & C & D2 & FPT \\
\hline (BiP)In & 7.20 & 8.11 & 8.25 \\
(BiAs)In & 4.09 & 4.49 & 4.58 \\
(BiSb)In & 0.31 & 0.34 & 0.34 \\
(InGa)Bi & 1.77 & 2.10 & 2.01 \\
(InA1)Bi & 1.55 & 1.71 & 1.74 \\
(GaA1)Bi & 0.01 & 0.02 & 0.01 \\
\hline
\end{tabular}

From the mixing enthalpies, we can obtain an estimate of the miscibility of the zincblende alloys. In a truly random alloy, the criteria for alloy mixing at a temperature, $\mathrm{T}$, is that $T \geq T_{c}$, where the critical temperature, $T_{c}$, is given by $\Omega /\left(2 R_{g}\right)$, where $R_{g}$ is the universal gas 
constant. For complete miscibility throughout the entire concentration range, the requirement is that the melting temperature of both the pure compounds of the alloys be greater than $T_{c}$,

$$
\frac{T_{m}}{T_{c}}>1
$$

where $T_{m}$ is the lower melting temperature of the constituent compounds. Values of $T_{c}$ for the bismuth alloys and the ratio $T_{m} / T_{c}$ are summarized in Table 7 .

Table 7

CRITICAL TEMPERATURE, $\mathrm{T}_{\mathrm{c}}$, MELTING TEMPERATURE, $\mathrm{T}_{\mathbf{m}}$, LATTICE MISMATCH PARAMETER, $\delta_{o}$, AND THE RATIO $\left|\delta_{0}\right| / \delta_{m}$

\begin{tabular}{|l|c|c|c|c|c|}
\hline Compound & $\left|\delta_{\mathrm{o}}\right|$ (percent) & $\mathrm{T}_{\mathrm{c}}(\mathrm{K})$ & $\mathrm{T}_{\mathrm{m}}(\mathrm{K})^{*}$ & $\mathrm{~T}_{\mathrm{m}} / \mathrm{T}_{\mathrm{c}}$ & $\left|\delta_{\mathrm{o}}\right| / \delta_{\mathrm{m}}$ \\
\hline$(\mathrm{BiP}) \mathrm{In}$ & 13.3 & 2080 & 1343 & 0.65 & 0.10 \\
$(\mathrm{BiAs}) \mathrm{In}$ & 9.0 & 1150 & 1215 & 1.06 & 0.10 \\
$(\mathrm{BiSb}) \mathrm{In}$ & 2.7 & 87 & 798 & 9.17 & 0.08 \\
$(\mathrm{InGa}) \mathrm{Bi}$ & 6.2 & 500 & - & - & - \\
$(\mathrm{InA}) \mathrm{Bi}$ & 5.7 & 440 & - & - & - \\
$(\mathrm{GaAl}) \mathrm{Bi}$ & 0.5 & 2 & - & - & - \\
\hline
\end{tabular}

*American Institute of Physics (1972). $\mathrm{T}_{\mathrm{m}}$ is the melting temperature of the nonbismuth compound.

Perhaps a better rule for miscibility (Chen and Sher, 1985a) is

$$
\left|\delta_{0}\right| / \delta_{\mathrm{m}}<1
$$

where

$$
\delta_{\mathrm{m}}=1.63 \chi_{\mathrm{m}}
$$

and $\chi_{\mathrm{m}}$ is the ratio of the rms bond-length amplitude fluctuation to the bond length at the melting temperature, $T_{m}$. The lattice mismatch parameter, $\delta_{0}$, is given by

$$
\delta_{0}=1-\mathrm{d}(\text { impurity }) / \mathrm{d}
$$

Values of the ratio $\left|\delta_{0}\right| / \delta_{\mathrm{m}}$ are summarized in Table 7. 
For both of the above criteria for miscibility, the relevant melting temperature is the lower of the two compound melting temperatures. No experimental melting temperatures are available for the zincblende bismuth compounds. Thus in the above calculations, SRI assumed that the relevant temperature was that of the nonbismuth compound, thereby implying that the melting temperature of the bismuth compounds are the higher of the two. From Table 7, we see that first criterion for miscibility $T_{m} / T_{c}>1$ is satisfied for the two anion-substituted zincblende alloys (BiAs)In and (BiSb)In, and that a miscibility gap is predicted for zincblende (BiP)In. We have not made miscibility predictions for the cation-substituted alloys having a common bismuth anion since no zincblende melting temperatures are available for the bismuth compounds. The second criterion for miscibility $\left|\delta_{0}\right| / \delta_{\mathrm{m}}<1$ is satisfied for all three of the anion-substituted alloys.

Of the three anion-substituted alloys, InSbBi shows the least tendency toward spinoidal decomposition (see Table 7). In addition, the assumption that $T_{m}$ of zincblende InBi be greater than $T_{m}$ of the other indium compound is the least stringent for $\operatorname{InSbBi}$, with $T_{m}(I n S b)=798$ $\mathrm{K}$, the strictest requirement for miscibility being that $\mathrm{T}_{\mathrm{m}}(\mathrm{InBi})>\mathrm{T}_{c}=87 \mathrm{~K}$. The low critical temperature of the alloy, InSbBi, indicate that this material will be miscible for temperatures near $300 \mathrm{~K}$. In contrast, the high critical temperature of InAsBi and the ratio of $T_{m} / T_{c}$ close to unity indicate a narrow miscibility range at a temperature $(-1200 \mathrm{~K})$ far from room temperature.

Our interpretation of the above results on miscibility is necessarily somewhat tentative. In the miscibility calculations, we have assumed that no allotropic phase transitions occur, that the constituent compounds form zincblende structures throughout the entire temperature and composition range. This is known not to be the case for the bismuth-bearing alloys, because the bismuth compounds themselves are not known to form zincblende structures. Thus, the above miscibility criterion should be used in conjunction with information on the allotropic phase transitions to correctly predict miscibility.

\section{E. Task 5-Cluster Formation}

SRI has generalized the above theory of dilute alloys to concentrated alloys using statistics based on combinations of tetrahedral clusters of five atoms (Chen and Sher, 1985b). This generalization is based on an extension of the regular solution theory based on pair energies to a theory for five-atom clusters. For an alloy $A_{x} B_{1-x} C$, the building blocks are clusters of $A_{m} B_{4-m} C$, where $m$ ranges from 0 to 4 , as shown in Figure 1. Effective cluster energies, e, and local bond lengths can then be computed for each of the cluster types. The partition function, $\mathrm{Z}$, that is obtained yields the mixing Helmholtz free energy, $\Delta \mathrm{F}$. A measure of the deviations from randomness, $\delta x$, is given by

$$
\delta \mathrm{x}=\mathrm{x}_{\mathrm{m}}-\mathrm{x}_{\mathrm{m}}^{(0)}
$$

where $x_{m}$ is the cluster distribution, $x_{m}{ }^{(0)}$ is the corresponding value for a random alloy,

$$
x_{m}^{(0)}=\left(g_{m}\right) x^{m} 1-x^{4-m},
$$




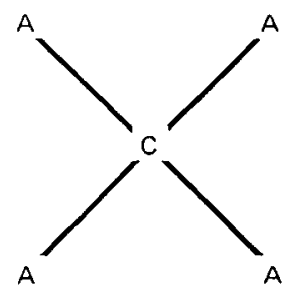

$m=4$

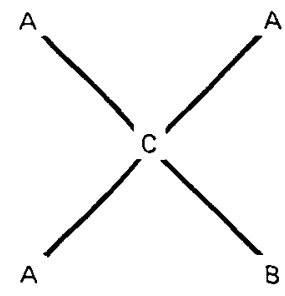

$m=3$

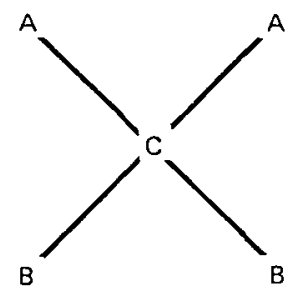

$m=2$

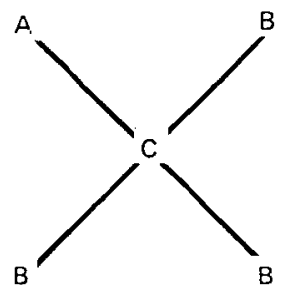

$m=1$

FIGURE 1 TETRAHEDRAL CLUSTER TYPES

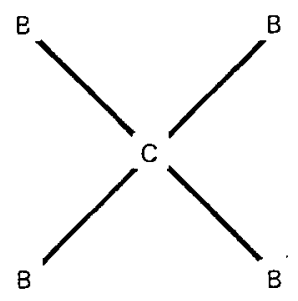

$m=0$

and $g_{m}$ is the cluster degeneracy

$$
\begin{array}{rl}
1 & m=0,4 \\
g_{m}=4 & m=1,3 \\
6 & m=2
\end{array}
$$

For the truly random alloy, $\delta x=0$ and, no micro- or macroclustering is expected to occur.

The results of SRI's microcluster calculations for InSbBi and InAsBi are summarized below. As discussed above, the cation-substituted alloys appear to be the most likely candidates for device materials, and these two alloys serve to illustrate the problems associated with the structural properties of bismuth-bearing alloys.

The effective energies of various five-atom clusters for $\mathrm{InBiSb}$ are shown in Figure 2. The energy for the cluster which contains four $\mathrm{Bi}$ and one In atoms, $\mathrm{Sb}(0) \mathrm{Bi}(4)$, is $e_{4} ; e_{3}$ is 


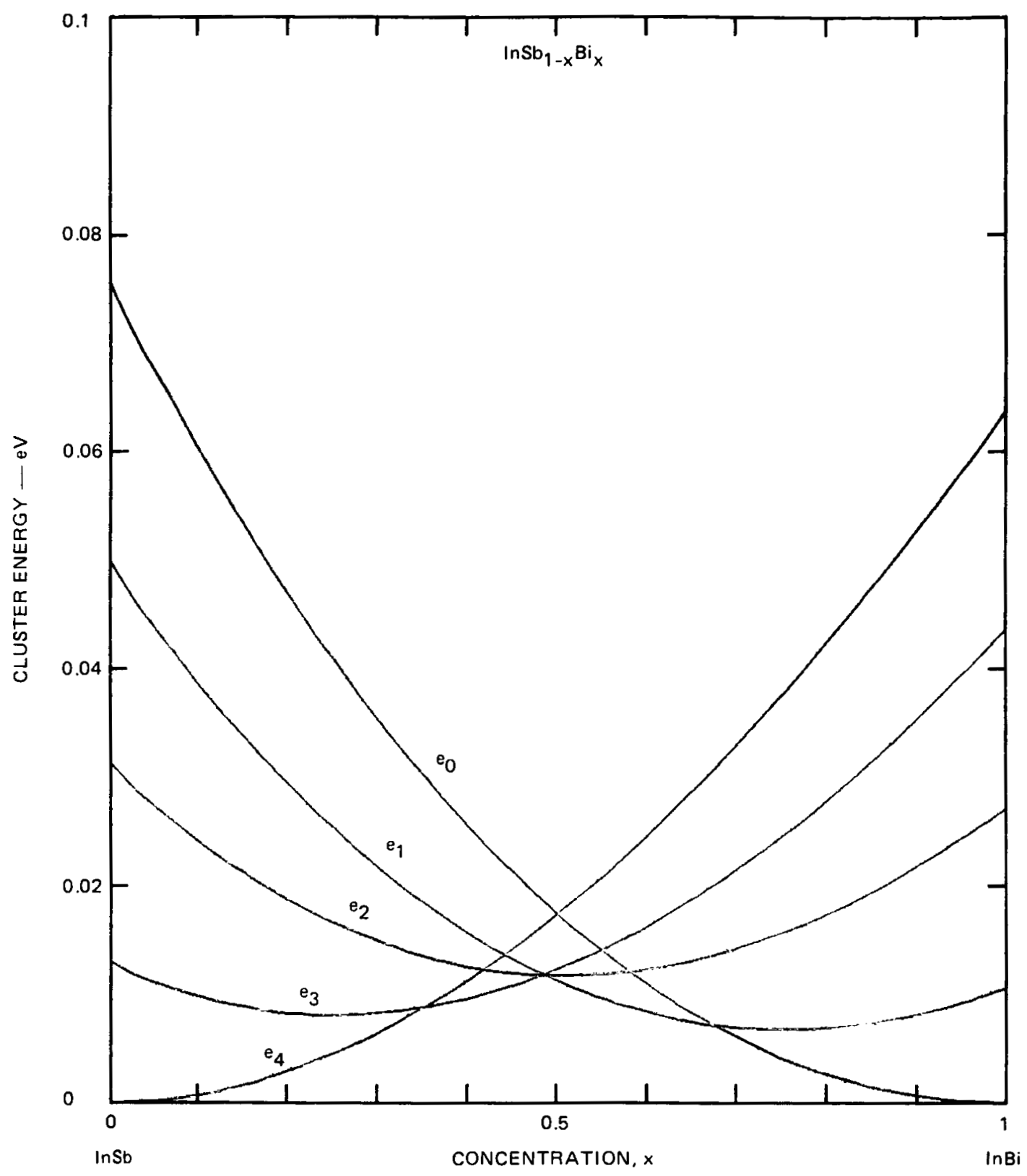

FIGURE 2 CLUSTER ENERGIES AS A FUNCTION OF CONCENTRATION FOR InSbBi 
the energy for the cluster $\operatorname{InSb}(1) \mathrm{Bi}(3)$; and so on. Only the nonlinear dependence of the energy on the number of atoms of either species in the cluster is responsible for the nonrandom distribution. The $\delta$ shown in Figure 3 are these nonlinear energies, defined as

$$
\begin{gathered}
\delta_{3}=e_{3}-\left(3 e_{4}+e_{0}\right) / 4, \\
\delta_{2}=e_{2}-\left(e_{4}+e_{0}\right) / 2
\end{gathered}
$$

and

$$
\delta_{1}=e_{1}-\left(e_{4}-3 e_{0}\right) / 4
$$

for $78 \mathrm{~K}, 300 \mathrm{~K}$, and $600 \mathrm{~K}$. The reference energy $\Delta=\mathrm{xe}_{4}+(1-\mathrm{x}) \mathrm{e}_{0}$ is important and has been included in the calculation of the mixing free energies. The energies shown in Figure 3 indicate that InSbBi would be a rather innocent alloy if the zincblende structure were the lowest-energy structure. Indeed, the deviations from randomness shown in Figure 3 indicate that the zincblende alloy should be very close to a random alloy at 78,300 , and $600 \mathrm{~K}$. Figure 4 shows that the bond lengths vary smoothly with concentration $x$.

According to the mixing free energy, $\Delta \mathrm{F}$ (shown in Figure 5), miscibility should not be a problem if InBi behaved like a zincblende compound. This result is consistent with the results obtained for the dilute alloy limit discussed in Task 4 above. In reality, InBi has a tetragonal structure similar to $\mathrm{PbO}$ (Wykoff, 1963). The only clue that $\mathrm{Bi}$ behaves differently from other group $\mathrm{V}$ atoms is that $\mathrm{Bi}$ has a much larger spin-orbit splitting $\left(\varepsilon_{\mathrm{p} 3 / 2}-\varepsilon_{\mathrm{p} 1 / 2}>2 \mathrm{eV}\right)$.

SRI repeated the above calculations for InAsBi; the results are summarized in Figures 6 through 9. Because the estimated bond length of $\operatorname{InBi}$ is much larger than that of InAs and the strain energy is the dominant contribution to the mixing energy (especially true for anionsubstituted alloys), large cluster energies emerge. However, the nonlinear parts are only about one-tenth the magnitude of the $\mathrm{e}^{\prime}$. The mixing free energies, $\Delta \mathrm{F}$ (shown in Figure 9), show that InBi and InAs are hard to mix, even without considering structures other than zincblende, again consistent with the dilute alloy results. Figure 8 shows that the bond length associated with a given bond at a given concentration is not very sensitive to the different clusters. This result is common to all the III-V pseudo-binary alloys and is also consistent with the available EXAFS data.

\section{F. Task 6-Semiconductor Hardness}

SRI calculated hardness values for the bismuth compounds using a hardness model discussed by Sher et al. (1985b). In this model, the Vicker's hardness is found to be dominated by the interaction energy of the dislocations generated by the indentation. Contributions to the 


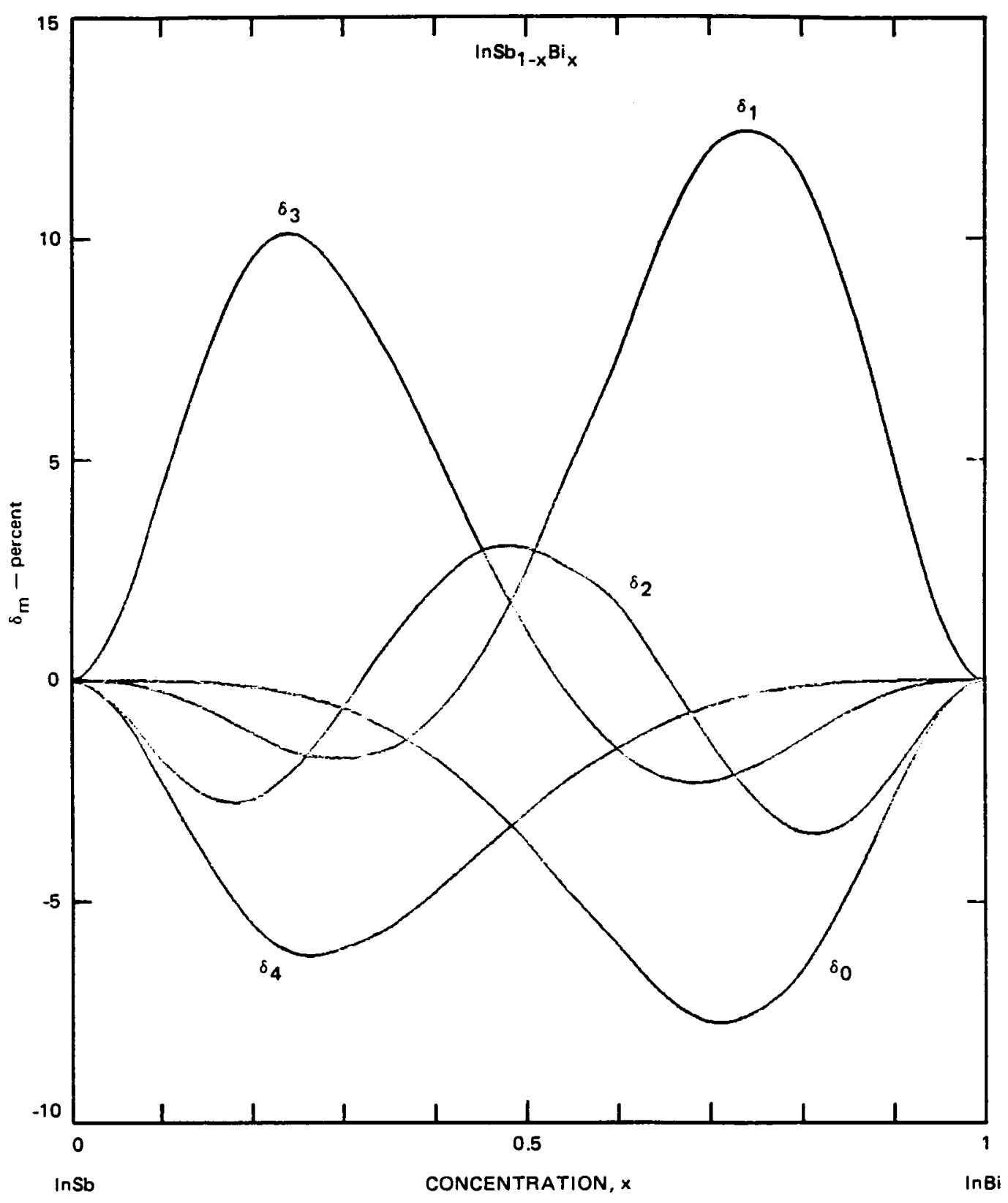

(a) $78 \mathrm{~K}$

FIGURE 3 DEVIATIONS OF CLUSTER POPULATIONS FROM A RANDOM DISTRIBUTION AS A FUNCTION OF CONCENTRATION FOR InSbBi 


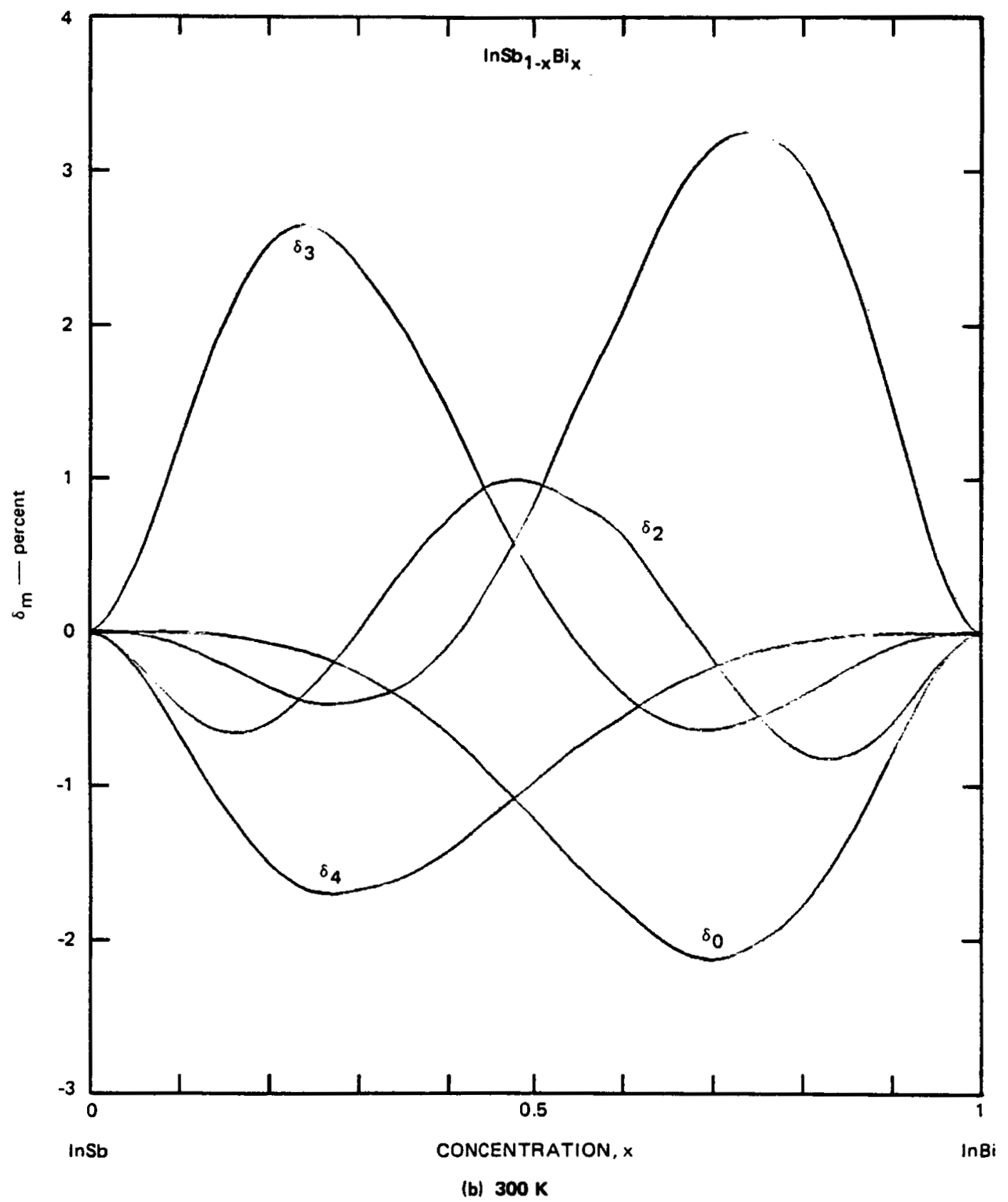

FIGURE 3 DEVIATIONS OF CLUSTER POPULATIONS FROM A RANDOM DISTRIBUTION AS A FUNCTION OF CONCENTRATION FOR InSbBi (Continued) 


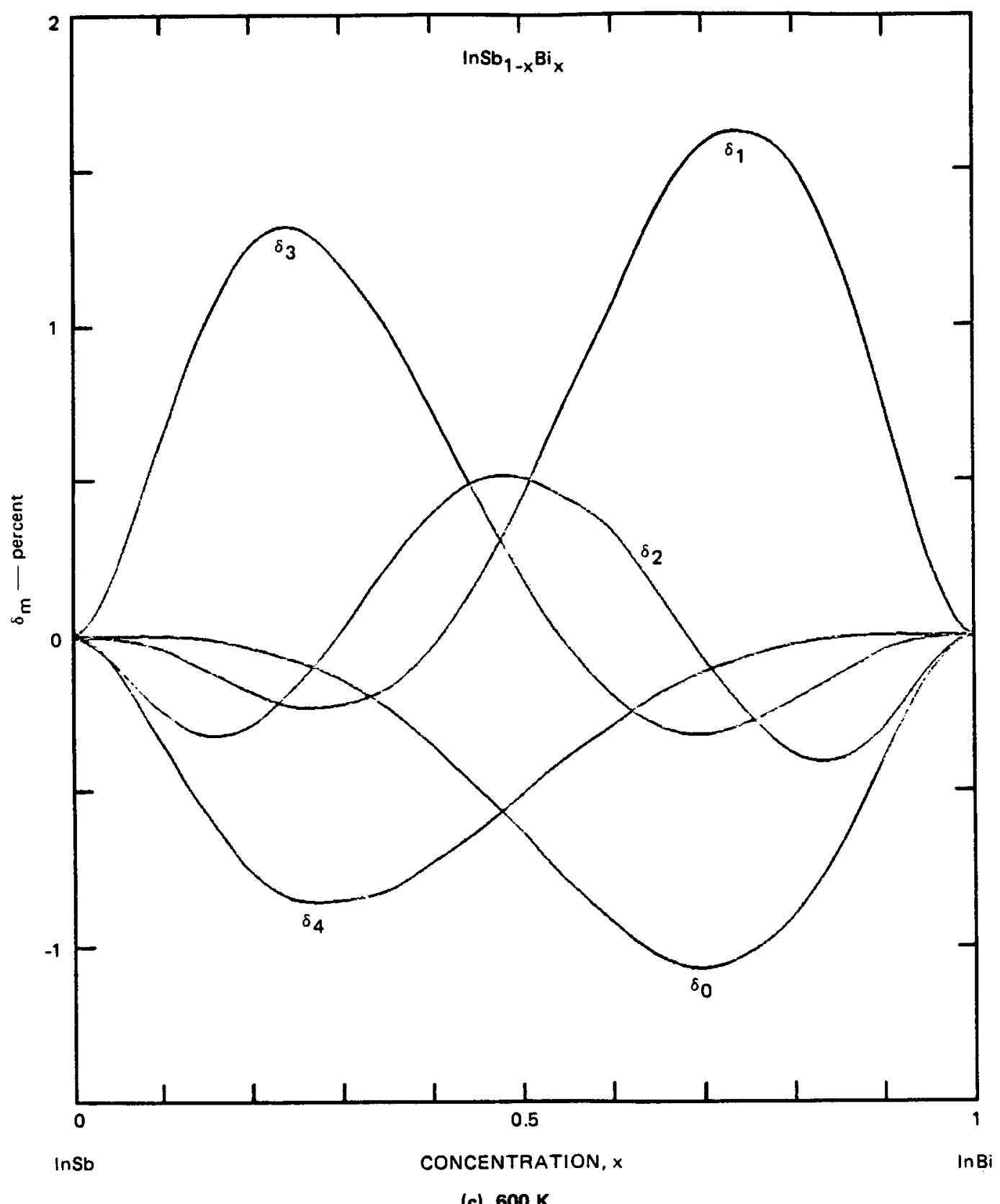

FIGURE 3 DEVIATIONS OF CLUSTER POPULATIONS FROM A RANDOM DISTRIBUTION AS A FUNCTION OF CONCENTRATION FOR InSbBi (Concluded) 


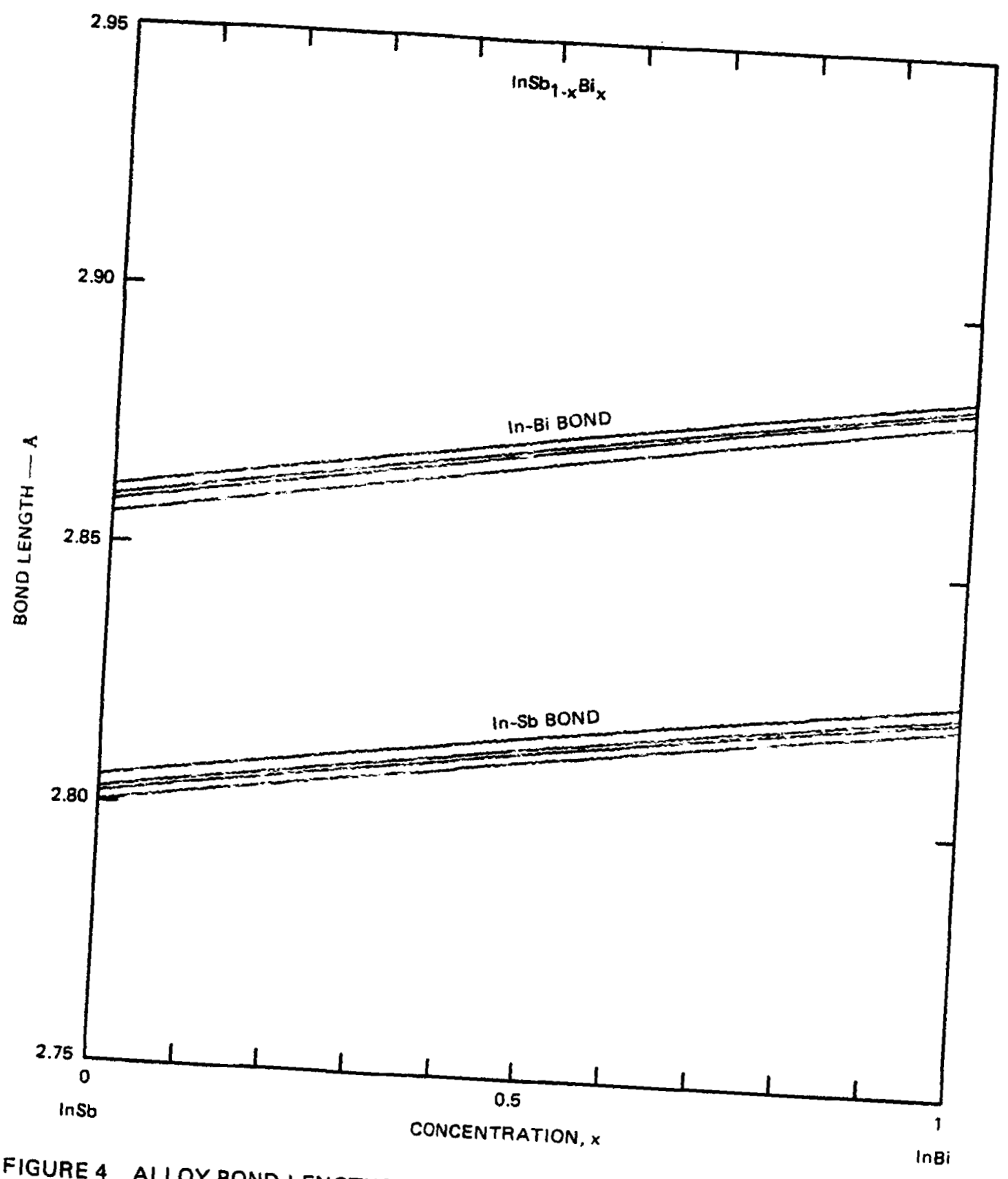

FIGURE 4 ALLOY BOND LENGTHS AS A FUNCTION OF CONCENTRATION FOR InSbBi 


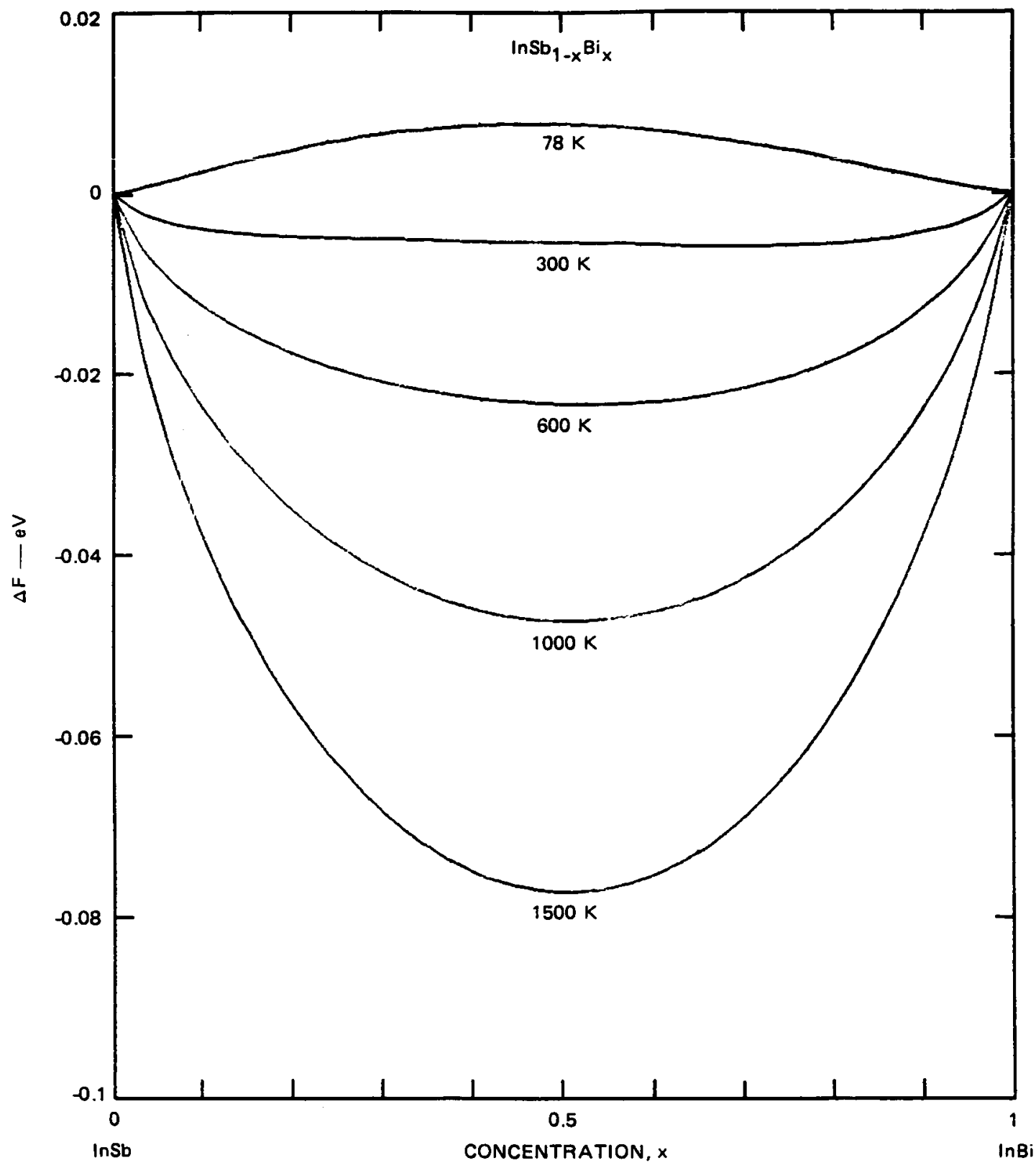

FIGURE 5 MIXING FREE ENERGIES AS A FUNCTION OF CONCENTRATION FOR InSbBi 


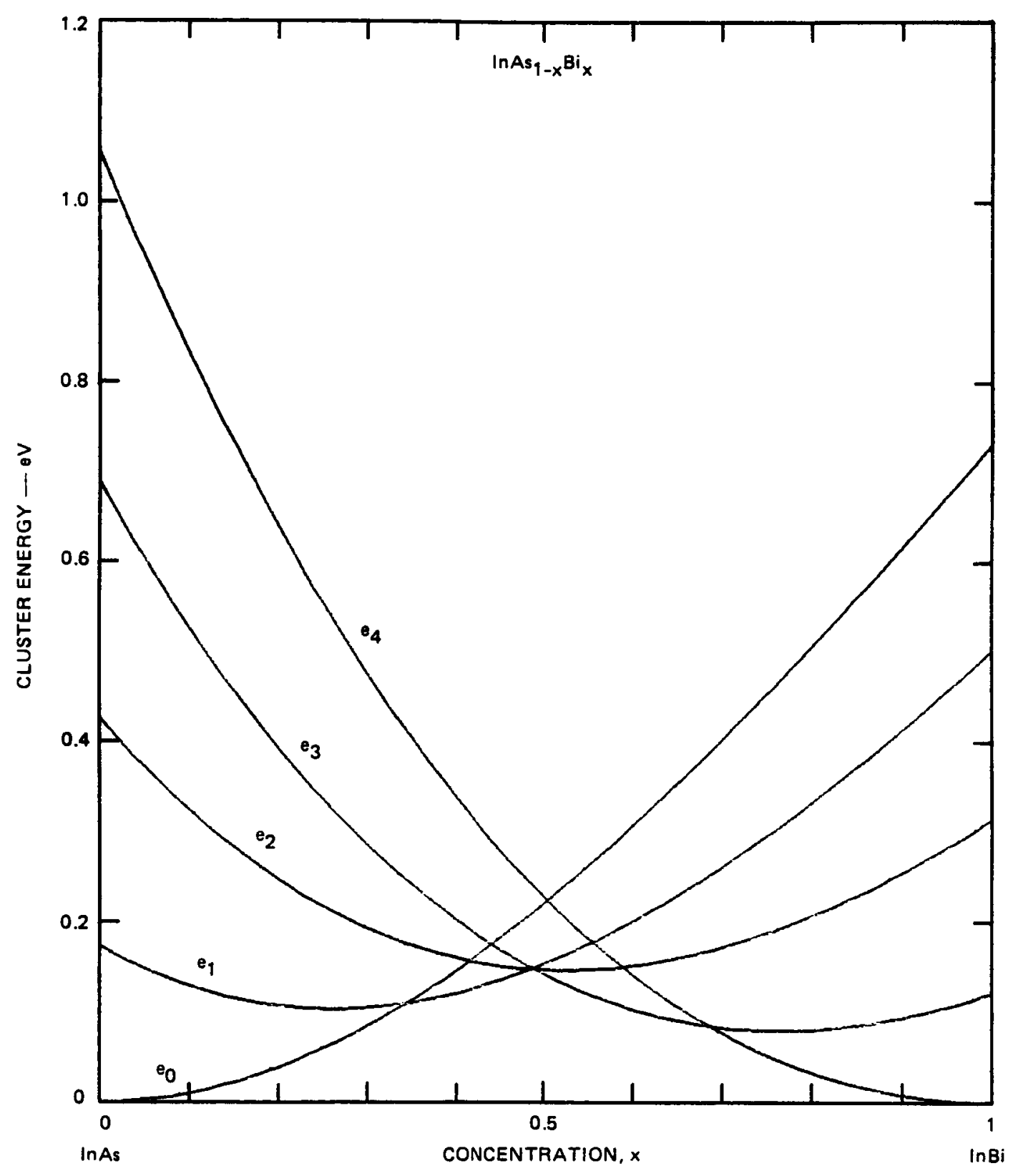

FIGURE 6 CLUSTER ENERGIES AS A FUNCTION OF CONCENTRATION FOR InASBi 


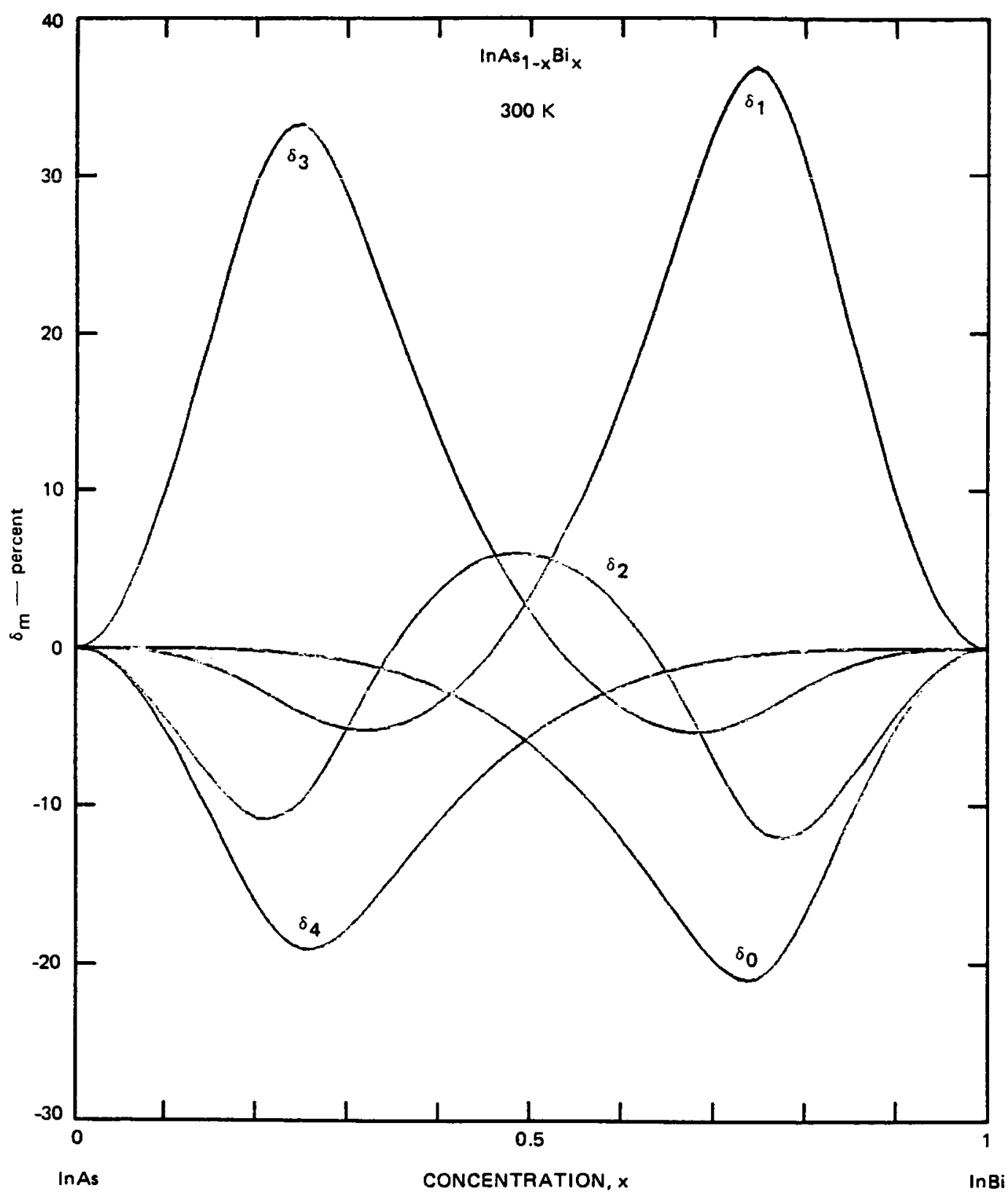

FIGURE 7 DEVIATIONS OF CLUSTER POPULATIONS FROM RANDOM DISTRIBUTIONS AS A FUNCTION OF CONCENTRATION FOR InAsBi 


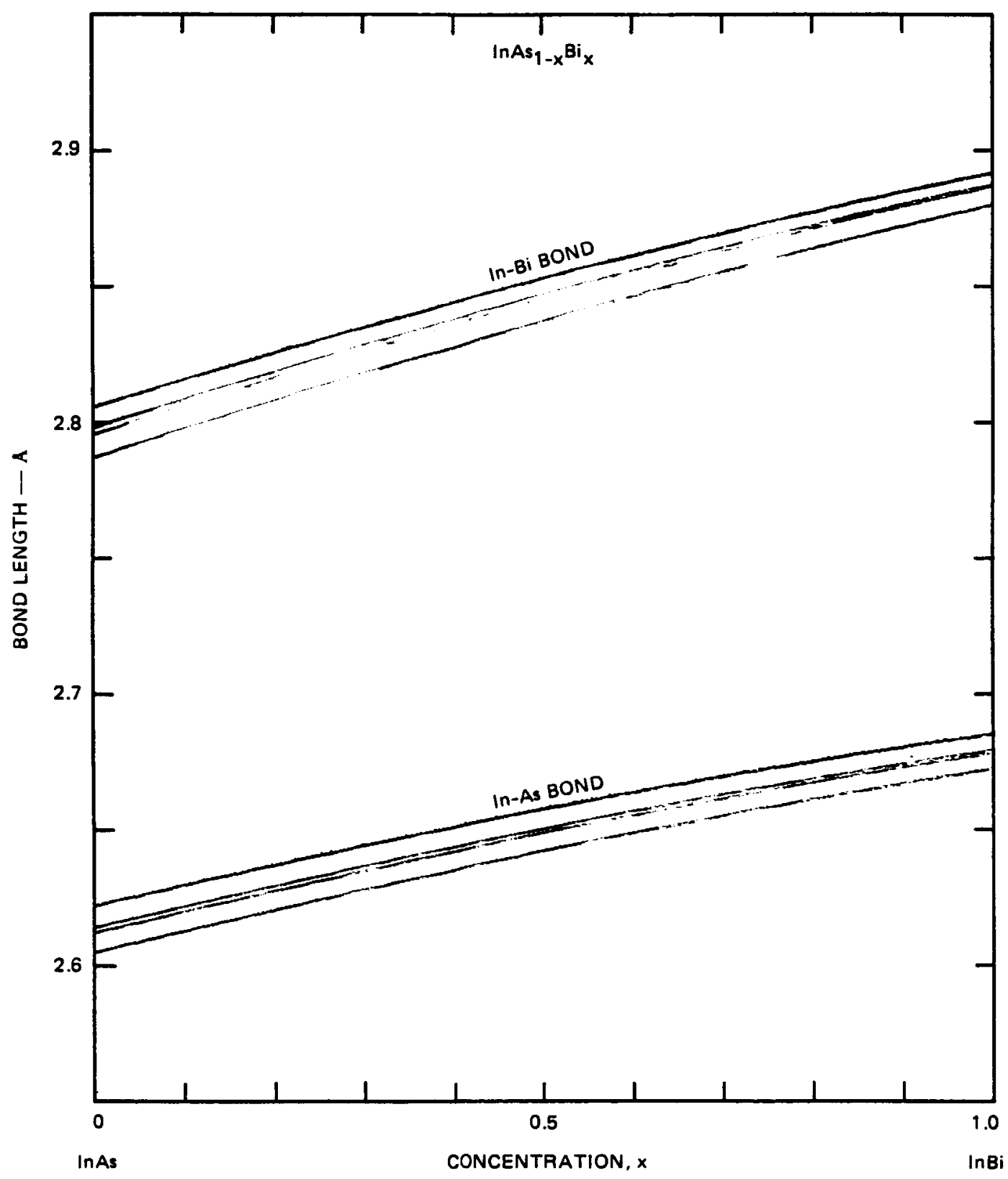

FIGURE 8 ALLOY BOND LENGTHS AS A FUNCTION OF CONCENTRATION FOR InAsBi 


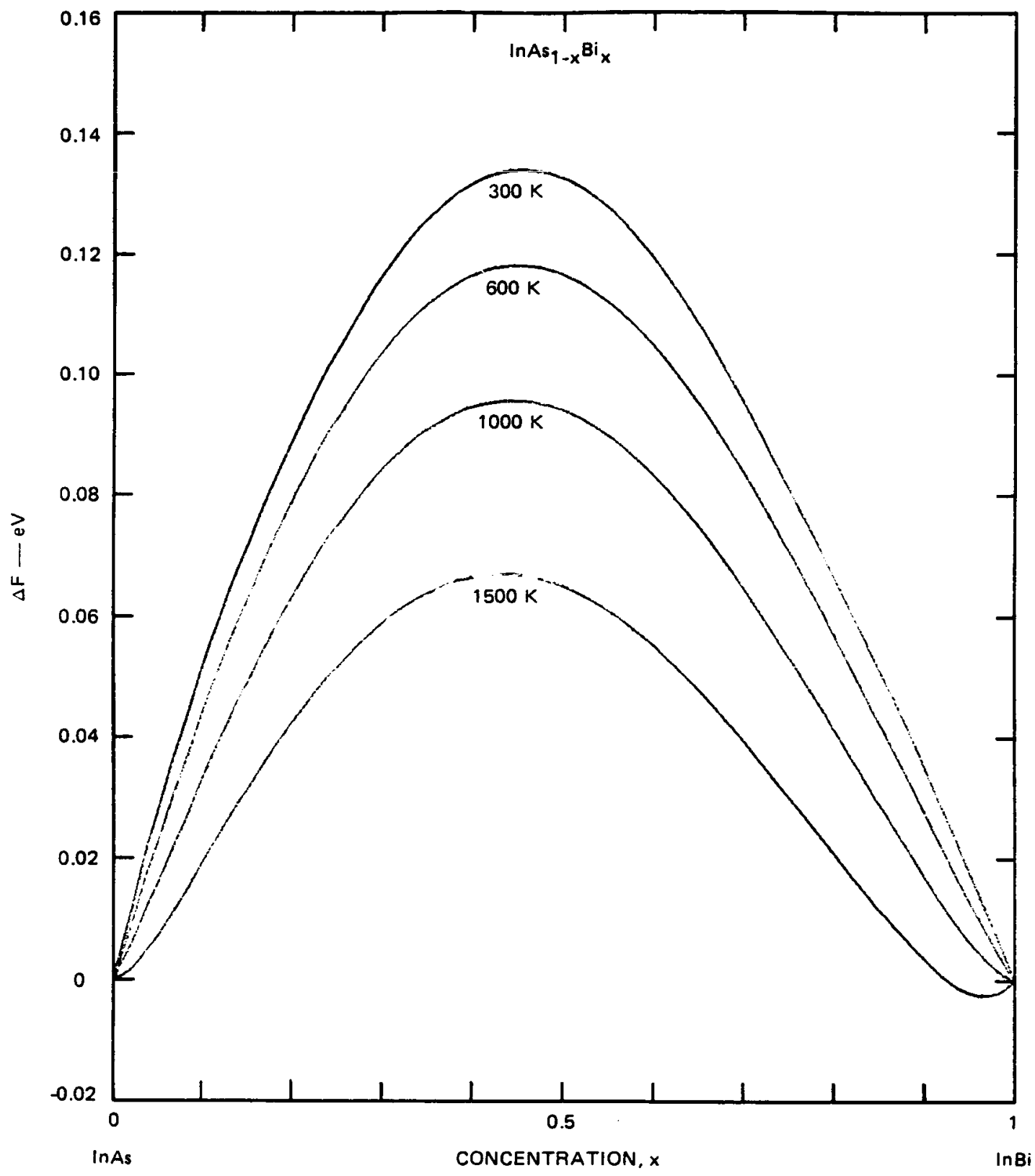

FIGURE 9 MIXING FREE ENERGY AS A FUNCTION OF CONCENTRATION FOR InAsBi 
hardness from the dislocation formation energy are found to be unimportant, and contributions to the work done by the indenter by virtue of heat generation have been ignored. Sher et al. obtain the following expression for a lower limit on the hardness:

$$
H_{\min }=\frac{G \cot (\Theta)}{6 \pi(1-\eta)}\left[-\ln \left[\frac{\cot (\Theta)}{\sqrt{2}}\right]+\frac{4}{3}+\sin ^{2}\left[\frac{\Theta}{2}\right]\right],
$$

where $G$ is the effective shear coefficient, $2 \Theta$ is the indenter tip angle, and $\eta$ is Poisson ratio. In this model, the hardness is insensitive to the Burger's vector; because the hardness is dominated by the dislocation interaction terms rather than the dislocation generation terms; the hardness is also insensitive to the applied force, $F$, which yields a hardness that is a true property of the material.

The hardness values were computed for indium and bismuth compounds using scaled theoretical elastic constants where experimental values were not available. For an isotropic medium, $C_{44}=0.5\left(C_{11}-C_{12}\right)$; and for the effective elastic constant, $G$, an average of these two values was used. The results for $\Theta=\pi / 4$ and $\eta=0.2$ are summarized in Table 8 .

Table 8

HARDNESS VALUES OF SEMICONDUCTORS

\begin{tabular}{|l|c|c|c|}
\hline Compound & $\begin{array}{c}\text { Effective elastic constant } \\
\left(10^{11} \text { dynes } / \mathrm{cm}^{2}\right)\end{array}$ & $\begin{array}{c}\mathrm{H}_{\text {min }}, \text { Calculated } \\
\left(\mathrm{kg} / \mathrm{mm}^{2}\right)\end{array}$ & $\begin{array}{c}\mathrm{H}, \text { Experiment } \\
\left(\mathrm{kg} / \mathrm{mm}^{2}\right)\end{array}$ \\
\hline $\mathrm{InP}$ & 3.71 & 459 & 467 \\
InAs & 3.19 & 393 & 353 \\
$\mathrm{InSb}$ & 2.28 & 282 & 213 \\
$\mathrm{InBi}$ & 1.98 & 245 & - \\
$\mathrm{GaBi}$ & 2.71 & 335 & - \\
$\mathrm{AlBi}$ & 2.67 & 329 & - \\
$\mathrm{GaP}$ & 5.45 & 673 & 910 \\
$\mathrm{GaAs}$ & 4.52 & 558 & 700 \\
$\mathrm{AlSb}$ & 3.01 & 372 & 343 \\
$\mathrm{GaSb}$ & 3.09 & - & 517 \\
$\mathrm{ZnTe}$ & 2.33 & - & 287 \\
$\mathrm{CdTe}$ & 1.24 & - & 154 \\
\hline
\end{tabular}

Because the bond length of $\mathrm{InBi}$ is longer than that of InSb, we will expect it to diminish the hardness of the alloy; $\mathrm{GaBi}$ and $\mathrm{AlBi}$, having shorter bond lengths, can be expected to increase the hardness of the alloys. 


\section{G. Task 7-Vacancy Formation Energy}

The ease of vacancy formation is an important issue in the growth of materials and may influence the choice of growth methods and parameters. These energies may also significantly influence subsequent device fabrication processes. The computation of the vacancy formation energies entails several steps as outlined below:

(1) Compute the vacancy formation energy, $E_{v}$, for the pure compounds in an unrelaxed configuration.

(2) Allow relaxation about the vacancy to occur and recompute the new vacancy formation energy self-consistently, which will lower $\mathrm{E}_{\mathbf{v}}$.

(3) Consider various classes of clusters for a given alloy concentration to compute the alloy vacancy formation energies, including relaxation.

Here, we will be concerned only with the first step; that is, to predict the vacancy formation energies in the unrelaxed clusters for both anion and cation vacancies. The energies we will calculate will be altered by the admission of relaxation to the crystal lattice, but the values we obtained here can be considered an upper limit on $\mathrm{E}_{\mathrm{v}}$ and will suffice to illustrate trends among compounds. We have used a simple model for calculating $E_{v}$ for a neutral vacancy in a tetrahedral semiconductor such as InSbBi, based on Harrison's tight-binding theory.

As an example, consider the cation vacancy in InSb. When an In atom is removed from the crystal and put into vacuum as a neutral atom, the energy required will be the difference between the final and initial energies, $E_{v}=E_{f}-E_{i}$. We will consider only those energies which are changed by the vacancy formation and will include the shifts to the bonding energies out to the second-shell bonds and shifts to the metallization out to the third-shell bonds about the vacancy. The change in the energies of the first-shell bonds connecting to the dangling hybrids is primarily due to changes in the metallization energy. However, because the hybrid energy $\varepsilon_{\mathrm{h}}$ is very close to the bond energy, $\varepsilon_{\mathrm{b}}$, we cannot use the perturbation theory for these energy shifts in the final state cluster.

If the second-neighbor interactions are not included, the dangling hybrids are not interacting with each other. We can then treat each of the four branches associated with each dangling hybrid separately. To avoid the error in the perturbation theory, we diagonalize a local Hamiltonian $\mathrm{H}$ for each branch. This $\mathrm{H}$ is spanned by seven hybrids: the dangling one, the three connecting to this one and sharing the common anion (and interacting with each other via $V_{1 a}$ ), and the three cation hybrids which face the last three anion hybrids and interact with them via $V_{2}$ :

$$
\begin{gathered}
\varepsilon_{\mathrm{h}}^{\mathrm{a}}=\left(\varepsilon_{\mathrm{s}}^{\mathrm{a}}+\varepsilon_{\mathrm{p} 1 / 2}^{\mathrm{a}}+2 \varepsilon_{\mathrm{p} 3 / 2^{\mathrm{a}}}\right) / 4 \\
\varepsilon_{\mathrm{h}}^{\mathrm{c}}=\left(\varepsilon_{\mathrm{s}}^{\mathrm{c}}+\varepsilon_{\mathrm{p} 1 / 2}^{\mathrm{c}}+2 \varepsilon_{\mathrm{p} 3 / 2}{ }^{\mathrm{c}}\right) / 4 \\
V_{2}=-24.5 / \mathrm{d}^{2}
\end{gathered}
$$




$$
\begin{gathered}
V_{1}^{a}=\left(\varepsilon_{\mathrm{s}}^{\mathrm{a}}-\varepsilon_{\mathrm{p}}^{\mathrm{a}}\right) / 4 \\
\mathrm{~V}_{1}^{\mathrm{c}}=\left(\varepsilon_{\mathrm{s}}^{\mathrm{c}}-\varepsilon_{\mathrm{p}}^{\mathrm{c})} / 4\right.
\end{gathered}
$$

Diagonalization of this $7 \times 7$ Hamiltonian yields seven modified energies, $\varepsilon_{i}$, i from 1 to 7 . The first three are the modified bond energies, which should be occupied by two electrons each. The fourth level corresponds to the modified dangling hybrid energy which, for the cation vacancy in a III-V compound such as InSb, is occupied by $5 / 4$ electrons per level. The fifth through seventh states are unoccupied antibonding states.

In our model, the energies of the bonds outside the $7 \times 7$ cluster are not changed to first order. The shift in the bond energies resulting from the diagonalization of the $7 \times 7$ does cause a shift in the metallization interaction between the antibonding states localized in the $7 \times 7$ cluster and the adjacent bonds outside the cluster. Similarly, the metallization interaction of the cluster bonding states with the outer antibonding states is modified.

The energy of the final state cluster, $E_{f}$, for a cation vacancy in a III-V compound is given by (keeping track of only those terms which change upon formation of a vacancy)

$$
\begin{gathered}
\mathrm{E}_{\mathrm{f}}=\varepsilon_{\mathrm{atom}}+5 \varepsilon_{4}^{\prime}+4 \times 2\left(\varepsilon_{1}^{\prime}+\varepsilon_{2}^{\prime}+\varepsilon_{3}^{\prime}\right) \\
+2 \times 4 \times 3\left(\varepsilon_{\mathrm{met}, 4}+\varepsilon_{\mathrm{met}, 5}+\varepsilon_{\mathrm{met}, 6}+\varepsilon_{\mathrm{met}, 7}\right),
\end{gathered}
$$

where $\varepsilon_{\text {atom }}$ is the valence electron energy of the free atom, and $\varepsilon_{1}^{\prime}, \varepsilon_{2}^{\prime}, \varepsilon_{3}{ }^{\prime}$, and $\varepsilon_{4}^{\prime}$ are the cluster bond energies, which have been shifted by the metallization with the third-shell antibonds,

$$
\begin{gathered}
\varepsilon_{\mathrm{i}}^{\prime}=\varepsilon_{\mathrm{i}}+3 \varepsilon_{\mathrm{mi}}, \\
\varepsilon_{\mathrm{mi}}=\frac{\left|\mathrm{V}_{1}^{\mathrm{c}}\right|^{2}\left|\mathrm{U}_{\mathrm{a}}^{\mathrm{c}}\right|^{2}}{\varepsilon_{\mathrm{i}}-\varepsilon_{\mathrm{a}}} \sum_{\mathrm{j}}\left|\mathrm{U}_{\mathrm{ji}}\right|^{2},
\end{gathered}
$$

where $\mathrm{j}$ sums over the three second-shell hybrids which connect to the third shell. The $\varepsilon_{\text {met,i }}$ are the shifts in the third-shell bond energies due to the interaction with the bonding states of the $7 \times 7$ cluster:

$$
\varepsilon_{\mathrm{met}, \mathrm{i}}=\frac{\left|\mathrm{V}_{1}^{\mathrm{c}}\right|^{2}\left|\mathrm{U}_{\mathrm{b}}{ }^{\mathrm{c}}\right|^{2}}{\varepsilon_{\mathrm{b}}-\varepsilon_{\mathrm{i}}} \sum_{\mathrm{j}}\left|\mathrm{U}_{\mathrm{ji}}\right|^{2}
$$


where the $\mathrm{j}$ summation is as in Eq. (23). For the initial state energy, $E_{i}$, we have

$$
\begin{aligned}
E_{i}=\varepsilon_{b}^{\prime} & +4 V_{0}+4 \times 2\left(\varepsilon_{b}^{\prime}+\varepsilon_{b}^{\prime}+\varepsilon_{b}^{\prime}\right) \\
& +2 \times 4 \times 3 \times 3\left(\varepsilon_{m}^{c}\right),
\end{aligned}
$$

where $\varepsilon_{\mathrm{b}}^{\prime}$ is the bonding state energy which has been shifted because of metallization through the anion and the cation sites:

$$
\begin{gathered}
\varepsilon_{\mathrm{b}}{ }^{\prime}=\varepsilon_{\mathrm{b}}+3 \varepsilon_{\mathrm{m}}^{\mathrm{c}}+3 \varepsilon_{\mathrm{m}}^{\mathrm{a}}, \\
\varepsilon_{\mathrm{m}}^{\mathrm{c}}=\frac{\left|\mathrm{V}_{1}^{\mathrm{c}}\right|^{2}\left|\mathrm{U}_{\mathrm{a}}^{\mathrm{c}}\right|^{2}\left|\mathrm{U}_{\mathrm{b}}^{\mathrm{c}}\right|^{2}}{\varepsilon_{\mathrm{b}}-\varepsilon_{\mathrm{a}}},
\end{gathered}
$$

and similarly for $\varepsilon_{m}{ }^{2} . V_{0}$ is the repulsive energy of the four central bonds that will be broken upon the creation of the vacancy.

The four eigenvalues localized on the dangling hybrids are degenerate, because there are no couplings between the four branches of the cluster when no dangling hybrid interactions are included. When these couplings are included, the dangling hybrid states are split into one $A_{1}$ and three $T_{2}$ triply degenerate states, according to the $T d$ point symmetry of the vacancy site. The degeneracy of the three $T_{2}$ states can further split when the cluster is permitted to relax in the presence of strain energies.

The vacancy formation energy is computed as the energy necessary to remove an atom from the perfect lattice to infinity, here assuming no lattice relaxation occurs. The vacancy formation energy will, in general, differ for the anion and the cation. We assume that the changes of the bond energies neighboring the vacancy will be adequately described by the bonds that we have considered. Thus, the vacancy formation energy $E_{v}$ is computed from the difference

$$
E_{v}=E_{f}-E_{i}
$$

The vacancy formation energies are summarized in Table 9. 
Table 9

VACANCY FORMATION ENERGIES FOR Bi COMPOUNDS AND OTHER GROUP IV, III-V, AND II-VI COMPOUNDS*

\begin{tabular}{|l|c|c|c|c|c|c|c|r|}
\hline \multirow{2}{*}{ Compound } & \multicolumn{7}{|c|}{ Vacancy Formation Energy (eV) } \\
\cline { 2 - 8 } & $\mathrm{E}_{\mathrm{v} 1}$ & $\mathrm{E}_{\mathrm{v} 2}$ & $\mathrm{E}_{\mathrm{v} 3}$ & $\mathrm{E}_{\mathrm{v}}$ & $\mathrm{E}_{\mathrm{v} 1}$ & $\mathrm{E}_{\mathrm{v} 2}$ & $\mathrm{E}_{\mathrm{v} 3}$ & $\mathrm{E}_{\mathrm{v}}$ \\
\cline { 2 - 9 } $\mathrm{C}$ & 0.00 & 0.00 & 0.00 & 0.00 & 36.75 & -3.63 & -0.38 & 32.75 \\
$\mathrm{Si}$ & 0.00 & 0.00 & 0.00 & 0.00 & 16.87 & -4.68 & -1.33 & 10.86 \\
$\mathrm{Ge}$ & 0.00 & 0.00 & 0.00 & 0.00 & 18.03 & -7.07 & -30.2 & 7.95 \\
$\mathrm{Sn}$ & 0.00 & 0.00 & 0.00 & 0.00 & 15.12 & -6.59 & -3.27 & 5.25 \\
$\mathrm{AIP}$ & 13.29 & -1.12 & -2.21 & 9.96 & 23.81 & -11.71 & -0.16 & 11.93 \\
$\mathrm{AlAs}$ & 12.34 & -1.14 & -3.46 & 7.74 & 24.20 & -13.45 & -0.13 & 10.61 \\
$\mathrm{AlSb}$ & 10.94 & -1.75 & -4.61 & 4.57 & 18.96 & -11.25 & -0.22 & 7.49 \\
$\mathrm{AlBi}$ & 12.16 & -1.66 & -7.64 & 2.86 & 20.79 & -13.38 & -0.16 & 7.24 \\
$\mathrm{GaP}$ & 12.98 & -2.23 & -3.78 & 6.96 & 21.92 & -11.74 & -0.29 & 9.89 \\
$\mathrm{GaAs}$ & 12.53 & -2.34 & -5.92 & 4.28 & 22.28 & -13.65 & -0.25 & 8.38 \\
$\mathrm{GaSb}$ & 12.16 & -3.40 & -7.03 & 1.72 & 17.40 & -11.47 & -0.43 & 5.50 \\
$\mathrm{GaBi}$ & 14.28 & -3.35 & -11.24 & -0.32 & 19.09 & -13.89 & -0.36 & 4.84 \\
InP & 11.00 & -1.49 & -3.79 & 5.71 & 22.61 & -13.01 & -0.13 & 9.47 \\
InAs & 10.54 & -1.54 & -5.86 & 3.14 & 23.01 & -14.89 & -0.08 & 8.04 \\
InSb & 10.07 & -2.37 & -7.56 & 0.15 & 17.94 & -12.57 & -0.15 & 5.22 \\
ZnTe & 8.66 & -0.67 & -2.69 & 5.31 & 20.08 & -14.91 & -0.04 & 5.14 \\
$\mathrm{HgTe}$ & 7.37 & -1.17 & -5.31 & 0.90 & 17.97 & -15.64 & -0.02 & 2.31 \\
CdTe & 7.66 & -0.48 & -2.50 & 4.69 & 20.43 & -15.56 & -0.01 & 4.86 \\
\hline
\end{tabular}

${ }^{*} \mathrm{E}_{\mathrm{v} 1}, \mathrm{E}_{\mathrm{v} 2}$, and $\mathrm{E}_{\mathrm{v} 3}$ refer to contributions to the total energy, $\mathrm{E}_{\mathrm{v}}$, from the first, second, and third shells. 


\section{CONCLUSIONS}

All three of the bismuth compounds $\mathrm{AlBi}, \mathrm{GaBi}$, and $\mathrm{InBi}$ show negative bonding energies from -1.2 to $-1.6 \mathrm{eV}$, indicating that, if made, the zincblende structures would be bound and perhaps more strongly bound than the II-VI compounds currently used for infrared detection devices. No calculations were done for structures other than zincblende for the Bi compounds, although the large spin-orbit splitting in $\mathrm{Bi}$, which results in a large promotion energy in the bond energy, and the lack of experimental observation of zincblende Bi compounds indicate that the zincblende structure is not the lowest energy state for the binary systems. Because of the negative binding energy of all of the $\mathrm{Bi}$ compounds, all three can be considered candidates for alloying with other III-V compounds for narrow-gap semiconductors.

None of the bismuth compounds are known to form zincblende structures, so none of the cation-substituted alloys are deemed likely to form even reasonably metastable zincblende structures. Thus, without a stable III-V compound as one alloy component, the anionsubstituted alloys $\mathrm{AlGaBi}, \mathrm{AlInBi}$, and $\mathrm{GaInBi}$ are not considered strong candidates for growth as narrow-gap semiconductors. The anion-substituted alloys however, are more promising.

Zilko and Green $(1978 ; 1980)$ found the semimetal-semiconductor transition occurring at - 11 mole percent in the metastable InSbBi. Assuming little band-gap bowing in the alloys, such that the band gap as a function of concentration, $x$, is approximately a straight line, a band gap of $-1.5 \mathrm{eV}$ is extrapolated for the semimetal zincblende InBi. Assuming little band gap bowing for all $\mathrm{Bi}$ alloys, we find the following approximate concentrations, $x$, to achieve a band gap of $0.1 \mathrm{eV}$ :

$\begin{array}{cc}\text { Alloy } & X \\ \operatorname{InP}_{1-\mathrm{x}} \mathrm{Bi}_{\mathrm{x}} & 0.44 \\ \operatorname{InAs}_{1-\mathrm{x}} \mathrm{Bi}_{\mathrm{x}} & 0.14 \\ \mathrm{InSb}_{1-\mathrm{x}} \mathrm{Bi}_{\mathrm{x}} & 0.05\end{array}$

Alloy hardening is observed in the zincblende semiconductors, where the hardness as a function of concentration $x$ shows an upward bowing relative to the straight-line average. Because hardness depends on the inverse of the bond length to some power, alloying a compound such as InP, InAs, or InSb with a longer-bond-length compound such as InBi may result in an alloy which is harder than the constituents. For a material with a band gap of $0.1 \mathrm{eV}$, one expects the hardest material from InPBi, the least hard from InSbBi. Thus, even though more than 40 percent $\mathrm{Bi}$ in InP is needed to achieve the desired band gap, the alloy hardening will result in a hard material, harder than the currently favored narrow-gap alloy $\mathrm{HgCdTe}$. In comparison, a $0.1 \mathrm{eV}$ alloy of InSbBi will be a relatively soft material, of comparable structural quality to $\mathrm{HgCdTe}$. Thus, based on the predicted structural properties, InPBi, if it can be grown at all, appears the most promising candidate for infrared device materials. 
The results of the miscibility calculations indicate that InSbBi will be the easiest of the anion-substituted alloys to grow, having the smallest bond length mismatch. A range of miscibility for InPBi and InAsBi exists at high temperatures. For InPBi, the results of the dilute alloy calculation indicate that InP and InBi has a miscibility gap, because the melting temperature of InP is lower than the critical temperature. The results of the cluster calculations indicate that even InAsBi (with a lattice mismatch of $\sim 9$ percent compared to $\sim 13$ percent for InPBi) will be hard to mix, because the lattice mismatch of the constituents.

Thus to grow the structurally superior InPBi alloy, one must resort to nonequilibrium growth methods, such as energy-assisted epitaxy employed by Zilko and Green (1978, 1980), where the effective growth temperature is kept high. By growing the alloy at an elevated temperature, one can achieve a regime of constituent miscibility. Although our results indicate that InPBi may be immiscible, if it is miscible only at elevated temperatures $(\sim 1300 \mathrm{~K})$, its promise to be a structurally superior narrow-gap semiconductor justifies a program for growth of this alloy. Because of the smaller bond length mismatch of their constituents, InAsBi and InSbBi shows less tendency toward immiscibility than InPBi. Unfortunately, InAsBi and InSbBi will probably be less hard than InPBi and of comparable hardness to $\mathrm{HgCdTe}$, thus reducing the incentive for growth of these materials. 


\section{REFERENCES}

American Institute of Physics Handbook, 1972: 3rd ed., edited by D.E. Gray (McGraw-Hill, New York), pp. 9-16.

Bachelet, G.B., D.R. Hamann, and M. Schlüter; "Pseudopotentials That Work: From H to Pu," Phys. Rev. B, 26, p. 4199.

Chen, A.-B., and A. Sher, 1983: "Bonding Theory of Semiconductor Alloys," Microscience, 3, p. 1 .

Chen, A.-B., and A. Sher, 1985a: "Semiconductor Pseudobinary Alloys: Bond Length Relaxation and Mixing Enthalpies,"' Phys. Rev. B, 32, p. 3695.

Chen, A.-B., and A. Sher, 1985b: "Semiconductor Alloys: Local Bond Lengths, Mixing Enthalpies, and Microclusters," Mat. Res. Soc. Symp. Proc., 46, p. 137.

Harrison, W., 1980: Electronic Structure and Properties of Solids (Freeman, San Francisco).

Harrison, W., 1983: "The Bonding Properties of Semiconductors," Microscience, 3, p. 35 [a multiclient publication of SRI International, Menlo Park, California].

Jean-Louis, A.M., and C. Hamon, 1969a: "Propriétés des Alliages $\operatorname{InSb}_{1-\mathbf{x}} \mathrm{Bi}_{\mathbf{x}}$; I. Measures Électriques,"' Phys. Stat. Sol., 34, p. 329.

Jean-Louis, A.M., B. Ayrault, and J. Vargas, 1969b: "Propriétés des Alliages $\operatorname{InSb}_{1-\mathrm{x}} \mathrm{Bi}_{\mathrm{x}}$; II Absorption Optique," Phys. Stat. Sol., 34, p. 341.

Joukoff, B., and A.M. Jean-Louis, 1972: "Growth of $\mathrm{InSb}_{1-\mathrm{x}} \mathrm{Bi}_{\mathbf{x}}$ Single Crystals by Czochralski Method," J. Cryst. Growth, 12, p. 169.

Keating, P., 1966: "Effect of Invariance Requirements on the Elastic Strain Energy of Crystals with Application to the Diamond Structure," Phys. Rev., 145, p. 636.

Martin, R., 1970: "Elastic Properties of ZnS Structure Semiconductors," Phys. Rev. B, 10, p. 4005.

Noreika, A.J., W.J. Takei, M.H. Francombe, and C.E.C. Wood, 1982: "Indium AntimonideBismuth Compositions Grown by Molecular Beam Epitaxy," J. Appl. Phys., 53, p. 4932.

Noreika, A.J., J. Greggi, W. Takei and M.H. Francombe, 1983: "Properties of MBE Grown InSb and $\operatorname{InSb}_{1-\mathrm{x}} \mathrm{Bi}_{\mathrm{x}}, "$ J. Vac. Sci. Technol., A-1, p. 558. 
Oe, K., S. Ando, and K. Sugiyama, 1981: "InSb ${ }_{1-\mathrm{x}} \mathrm{Bi}_{\mathrm{x}}$ Films Grown by Molecular Beam Epitaxy," Jap. J. Appl. Phys., 20, p. L303.

Sher, A., A.-B. Chen, W.E. Spicer, and C-K Shih, 1985a: "Effects Influencing the Structural Integrity of Semiconductors and Their Alloys," J. Vac. Sci. Technol., A3, p. 105.

Sher, A., A.-B. Chen, and W.E. Spicer, 1985b: "Dislocation Energies and Hardness of Semiconductors," Appl. Phys. Lett., 46, p. 54.

Wyckoff, R., 1963: Crystal Structures, Vol. 1 (J. Wiley, New York).

Zilko, J. and J. Greene, 1978: "Growth of Metastable $\mathrm{InSb}_{1-\mathbf{x}} \mathrm{Bi}_{\mathbf{x}}$ Thin Films by Multitarget Sputtering," Appl. Phys. Lett., 33, p. 254.

Zilko, J. and J. Greene, 1980: "Growth and Phase Stability of Epitaxial Metastable $\mathrm{InSb}_{1-\mathrm{x}} \mathrm{Bi}_{\mathrm{x}}$ Films on GaAs. I. Crystal Growth. J. Appl. Phys., 51, p. 1549. 


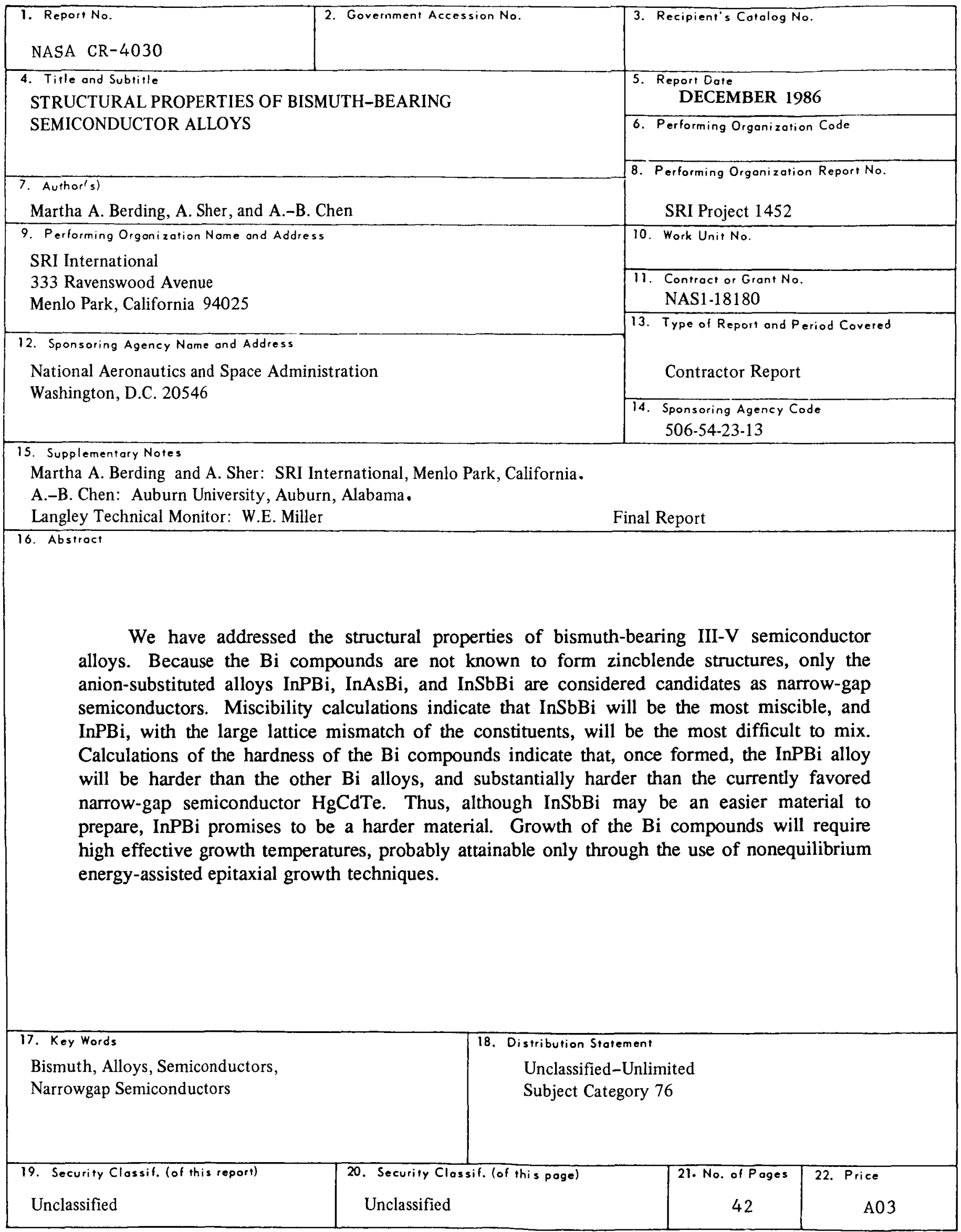

"For sale by the National Technical Information Service. Springfield, Virginia 22161 